\title{
Impact of Erasmus mobility for study on the development of Tuning Europe generic competences, as assessed by outgoing and incoming students in a large university: a revealing analysis*
}

\author{
Luigi F. Donà dalle Rose**
}

doi: 10.18543/tjhe-3(1)-2015pp57-98

\begin{abstract}
We explore on the basis of a simple survey tool the perceived impact of the Erasmus mobility experience on the improvement of the thirty generic competences of the Tuning Europe list. We rely on a self-assessment procedure, i.e. on data collected by the Erasmus Office of the University of Padova, Italy, through end-of-stay questionnaires, as returned by both outgoing and incoming Erasmus students. Processed data yield the percentage number of ticks, by which a given competence was chosen by the answering samples. We introduce a quantity "importance of improvement", which measures the perceived degree of development of a given generic competence during the mobility experience and allows a consistent comparison among different samples. On this basis, we can order the thirty competences according to decreasing perceived importance of improvement in the two above samples. From a general point of view, Erasmus students perceive the most important improvement in instrumental competences. We can then carry out meaningful comparisons between the profiles of competences' improvement of outgoing and incoming students, both in qualitative and in quantitative terms. Such a comparison reveals interesting features linked to the academic and human environments of mobile students. A further step in the analysis describes how country effects give more insight into the previous results. In such a context, we analyze the country impact on each given competence for both outgoing (visiting the country) and incoming (from the country) students, on the country subgroup
\end{abstract}

* I gratefully acknowledge the availability of the International Relations Office of the University of Padova and of its Head Mrs. Roberta Rasa to access its data banks on Erasmus students. More particularly, I express my gratefulness to Mrs. Sabrina Marchiori, who preciously and patiently fed and updated the administrative data, and Mr. Mattia Gusella, who extracted the relevant data from the questionnaires' returns.

** Luigi F. Donà dalle Rose (dona@pd.infn.it) is a retired Professor in Theoretical Solid State Physics (University of Padova, Italy) and a European expert in higher education and student mobility issues. 
competences' profile and on the exchange of competences, which occurs between paired country subgroups.

Keywords: Generic competences; competence development; Erasmus exchange mobility; student self-assessment; country effects.

\section{Introduction}

Competence based learning is at the heart of the paradigm shift which is occurring at all levels of education since some decades. At higher education level the focus on the developments of both generic and subject specific competences became prominent at the beginning of this century and was the concept around which several pilot projects developed, among them Tuning Europe (2000-2008), ${ }^{1}$ which then became a worldwide process. Several aspects of the academic life took new inspiration and thrust from these projects, within an overall reform process of the educational offer at country as well as at institutional level. Within this general context, the basic processes included: planning of the degree courses and their maintenance (in a quickly growing knowledge society and with increasing quality demand); a deep re-visitation of learning and teaching methodologies; rethinking of the assessment tools; a concrete dialogue with entrepreneurs and other societal stakeholders. All these processes fed, and still are feeding, this epochal paradigm shift. By now, not only in the European HE area, but at a worldwide level, many fruitful dialogues occurred, involving comparisons, common perceptions and shared agreements among the grass-root actors at institutional level, mainly students and academics, but also rectors, degree planners, quality agencies and so on. In Europe, a powerful promoter of comparisons and reciprocal knowledge at academic level came from the several existing inter-university networks and from the many related students' exchange programmes, noticeably the Erasmus programme run by the European Commission. $^{2}$

The basic pillar of the Erasmus programme is the full recognition at the home university of studies taken abroad. In this very context, much debate was devoted to whether the difficulties connected to studying in a different

${ }^{1}$ Julia González and Robert Wagenaar, eds., Tuning Educational Structures in Europe. Universities' Contribution to the Bologna Process. An Introduction, 2nd ed. (Bilbao: Universidad de Deusto, 2008).

${ }^{2}$ See for an updated guide: European Commission, Erasmus + Programme guide, valid as 1 January 2014, accessed October 24, 2015 at http://ec.europa.eu/programmes/erasmus-plus/ discover/guide/2014/documents/erasmus-plus-programme-guide_en.pdf 
academic environment and using a new language might be recognized in some official manner. Practically all approaches strictly rely on the recognition of those educational activities, which are formally assessed at the guest institution. Nevertheless, some universities introduced flexibility instruments (e.g. bonus credits, see EMQT project final report $)^{3}$ related to the development of transversal or generic skills, which occur while studying abroad under an exchange programme. A general and comprehensive study on the impact of Erasmus mobility on the professional preparation of mobile students was prepared on request by the European Commission as early as 2006 by the International Centre for Higher Education Research of Prof. Ulrich Teichler. ${ }^{4}$ An impressive Erasmus Impact Study on these same (and other) issues was recently edited under the responsibility of a wide consortium of partners, led by CHE Consult. ${ }^{5}$ By using a sophisticated and varied methodology, which is able to involve all involved stakeholders, the study identifies, among many quite interesting findings, also those skills, that from an Erasmus student perspective are "very improved/improved". ${ }^{6}$ In the present piece of work, we explore which are the Tuning competences that are perceived as more affected in those students who experience Erasmus study mobility. As explained below, the tool we use is a very simple one, in line with the pragmatic approach of the Tuning community, which mixes pedagogical experts with experts from other subjects. For those interested in, more refined possible approaches and rich specialist bibliographies can be found in some comprehensive publications and reports. ${ }^{7}$

${ }^{3}$ See chapter "Academic quality in exchange mobility" in Outcomes of the EMQT project, ed. Managing Committee of the EMQT-Erasmus Mobility Quality Tools Project, a structural network funded by the European Commission (Padova: Universities of Bologna, Deusto and Padova, 2012), 113.

${ }^{4}$ Oliver Bracht et al., The Professional Value of ERASMUS Mobility, INCHER International Centre for Higher Education Research (University of Kassel, 2006).

${ }^{5}$ European Commission, Erasmus Impact Study: Effects of mobility on the skills and employability of students and the internationalisation of higher education institutions (Luxembourg: Publications Office of the European Union, 2014), accessed November 12, 2015, doi: 10.2766/75468. The study was carried out under Service Contract EAC-2012-0545 and was run by a consortium, including CHE Consult (leader), Brussels Education Services (BES), Centrum für Hochschulentwicklung (CHE), Compostela Group of Universities (CGU), Erasmus Student Network (ESN). The Study Team was led by Uwe Brandenburg (CHE Consult).

${ }^{6}$ See, as an example, Table 3-15 in European Commission, Erasmus Impact Study, 108. Their Erasmus students' sample included several thousands of students. This Study examined fifteen generic skills.

7 We only quote here the illuminating book by Aurelio Villa Sanchez and Manuel Poblete Ruiz, eds., Competence-based learning, A proposal for the assessment of generic competences 
At the University of Padova, the development, as perceived by Erasmus students, of their own generic competences has been monitored since some years. In 2013-14, Padova University ranked $6^{\text {th }}$ among the top 100 Erasmus sending institutions and $40^{\text {th }}$ among the receiving ones. These facts offer an appropriate statistical basis for the present study.

As a matter of routine, the International Relations Office at Padova University asks all its Erasmus students - both incoming and outgoing - to answer an end-of-stay on-line questionnaire in order to monitor and assess their experience abroad. The incoming students answer at the end of their stay in Padova, as a required step in their leaving procedure; the outgoing students answer as soon as they are back in Padova, as a step of their coming back procedure.

The questionnaire mirrors the questionnaire used by the already quoted Tuning Europe project. The questionnaire for incoming students is formulated both in Italian and English language, while the questionnaire for outgoing students is in Italian language. Both questionnaires ask for a two-step answer:

step 1: Please indicate five skills that, on your opinion, you've improved among the thirty proposed.

step 2: After identifying them, please write the correspondent five numbers in the appropriate boxes ( $1=$ most important, $5=$ less important). The intention was that students should then place these five skills in rank order of importance.

A list with the short names of the 30 generic competences of the Project Tuning Europe ${ }^{8}$ follows: each competence has a box in the questionnaire, where to insert its order of importance among the 5 competences chosen by the respondent. This list, originally in English, was then translated into Italian (relying on an Italian version of the first Tuning Europe report), ${ }^{9}$ with

(Bilbao: Deusto University Press, 2008), and the quite stimulating report of the ModES project, funded by the European Commission: David Haselbergeret al., ModES Handbook: Mediating Soft Skills at Higher Education Institutions, Guidelines for the design of learning situations supporting soft skills achievement (2012). Accessed November 12, 2015, http://www. modesproject.eu/en/the-modes-handbook.aspx.

8 Julia González and Robert Wagenaar, eds., Tuning Educational Structures in Europe. Universities' Contribution to the Bologna Process. An Introduction, 2nd ed.,(Bilbao: Universidad de Deusto, 2008), 31-32.

9 Julia González and Robert Wagenaar, eds., Tuning Educational Structures in Europe, Final Report, Pilot Project - Phase 1, carried out by over 100 Universities, coordinated by the University of Deusto (Spain) and the University of Groningen (The Netherlands) and supported by the European Commission (University of Deusto and University of Groningen, 2003), 72-73. 
few changes (i.e. oral and written communication in your native language simply became oral and written communication; ability to communicate with experts in other fields became ability to communicate with not expert people). Both questionnaires adopted these changes.

In fact, the responding students interpreted quite differently step 2 of the question, showing its lack of clearness. Some students interpreted it correctly, i.e. giving their ranking for the five previously selected competences; others understood that the proper space should contain an assessment of the importance of that selected competence on a scale from 1 to 5 . Thus, in the following, we shall not rely on step 2 answers, but we shall simply infer the importance of the improvement of a given competence from the number of ticks it received in the returns of a given student sample to the questionnaire. A natural definition for such an importance would then be the percentage of students who ticked that very competence over the number of students who answered the question regarding competences. This simple and straightforward definition has the inconvenience that when applied separately to two or more samples does not guarantee a correct comparability, since the number of students ticking less than five competences, even though a small number, varies according to the sample, yielding a varying sum of all the competence percentages. In the following we shall discuss the results regarding two main samples, i.e. Erasmus outgoing and incoming students, plus a number of subsamples, for example country subgroups within each one of the two main samples. Thus, we need a renormalized variable - say $\mathbf{I}_{\text {score }}-$ which can be defined, for each considered sample, as

$$
\begin{gathered}
\mathbf{I}_{\text {score }}=\mathrm{f}_{\text {sample }} \mathrm{x} \text { (\% of students who ticked / number of answering } \\
\text { students in the sample), }
\end{gathered}
$$

where the renormalization factor $\mathrm{f}_{\text {sample }}$ is a quantity depending on the sample and close to one in our samples and subsamples. Do see Appendix I for more details. Throughout the present piece of work, the importance of improvement regarding a given competence in a given sample is expressed by the value of the variable $\mathbf{I}_{\text {score, }}$, given as a percentage. When the context is clear, we shall simply use the term importance.

As we shall see in detail below, our analysis yields for all considered samples an "order of importance" for the generic competences, the actual value of each competence importance measuring the impact that the mobility experience has on the set of the Tuning competences in terms of their improvement, as perceived by the responding students. In other words, it reflects the "importance of the perceived improvement" or even a perceived rate of development of each competence during mobility. 
Table 1 summarizes the answering data for the two main samples in the academic year 2013-14.

Table 1

Return data for the samples of OUTgoing and INcoming students

\begin{tabular}{|l|c|c|}
\hline \multicolumn{1}{|c|}{ Return data } & OUT & IN \\
\hline Number of students in the sample & 1163 & 680 \\
\hline Answering students & 988 & 595 \\
\hline Answering rate & $85,0 \%$ & $87,5 \%$ \\
\hline $\begin{array}{l}\text { Number of meaningful ticks (i.e. competences } \\
\text { selected as improved ones) }\end{array}$ & 4788 & 2595 \\
\hline $\begin{array}{l}\text { Number of ticks per answering student (out of } \\
\text { the 5 suggested ones) }\end{array}$ & 4,85 & 4,36 \\
\hline
\end{tabular}

Do notice here the large number of returns for both samples of students, the good and quite similar answering rate and the fact that not all students selected five competences, the incoming students selecting as an average 4.36 competences each against 4.85 selected by the outgoing students.

\section{General results}

Table 2 below summarizes the order of perceived importance of improvement for both outgoing and incoming students. The actual values for the corresponding importance of improvement, as defined above, are given for both samples in Table 5 below, where we shall discuss them thoroughly. Table 2 shows that most competences have the same or very similar position (yellow background in the first two columns) in the two orderings or rankings. Some competences do not obey this rule and this reveals interesting facts, as we discuss below. Moreover, it should be stressed that the actual value for the importance of improvement for a given competence can be quite diverse in the two rankings, even if the competence itself gets a similar position. 


\section{Table 2}

Order of importance for the improvement of the Tuning Europe generic competences according to the perception of the OUTgoing and INcoming Erasmus students at the University of Padova, academic year 2013-14 (ordered according to the perceived importance of OUT students)

\begin{tabular}{|c|c|c|}
\hline $\begin{array}{c}\text { OUT } \\
\text { order of } \\
\text { importance }\end{array}$ & $\begin{array}{c}\text { IN } \\
\text { order of } \\
\text { importance }\end{array}$ & Tuning generic competences \\
\hline 1 & 2 & Capacity to adapt to new situations \\
\hline 2 & 1 & Knowledge of a second language \\
\hline 3 & 5 & Problem solving \\
\hline 4 & 4 & Oral and written communication \\
\hline 5 & 6 & Appreciation of diversity and multiculturality \\
\hline 6 & 3 & Understanding of cultures and customs of other countries \\
\hline 7 & 10 & Capacity for organization and planning \\
\hline 8 & 7 & Interpersonal skills \\
\hline 9 & 9 & Ability to work in an international context \\
\hline 10 & 8 & Decision-making \\
\hline 11 & 17 & Capacity for applying knowledge in practice \\
\hline 12 & 16 & Critical and self-critical abilities \\
\hline 13 & 18 & Teamwork \\
\hline 14 & 15 & Research skills \\
\hline 15 & 24 & Information management skills \\
\hline 16 & 22 & Capacity for generating new ideas (creativity) \\
\hline 17 & 13 & Ability to work autonomously \\
\hline 18 & 20 & Will to succeed \\
\hline 19 & 12 & Capacity to learn \\
\hline 20 & 11 & Basic general knowledge \\
\hline 21 & 26 & Concern for quality \\
\hline 22 & 28 & Ability to work in an interdisciplinary team \\
\hline 23 & 23 & Grounding in basic knowledge of the profession \\
\hline 24 & 14 & Capacity for analysis and synthesis \\
\hline 25 & 19 & Initiative and entrepreneurial spirit \\
\hline 26 & 27 & Leadership \\
\hline 27 & 29 & Project design and management \\
\hline 28 & 25 & Ethical commitment \\
\hline 29 & 21 & Ability to communicate with not experts \\
\hline 30 & 30 & Elementary computing skills \\
\hline
\end{tabular}


Do notice the background colours of the competences: pink for the instrumental competences, sky blue for the interpersonal and green for the systemic competences. This complements Table 3 , which gives the percentage weight of the three groups of generic competences (instrumental, interpersonal and systemic), based on the importance of improvement for their own competences, as perceived by the two main samples of the present survey. The percentage weight of each group is simply the sum of the competences' importance in each group, each sum being here renormalized in order to yield a total of the three sums equal to $100 \%$.

Table 3 shows a comparison between the perceived weights of the three groups, considering all 30 competences. In general, we can say that the mobility students perceive the development of instrumental competences as more important. The last column shows the reference weight for the three groups, i.e. the weight, which corresponds to a uniform $\mathbf{I}_{\text {score }}$ value for all competences (see definition of uniformity value in Section III).

\section{Table 3}

Percentage weight of instrumental, interpersonal, systemic competences in the importance of improvement perceived by the two samples of outgoing (OUT) and incoming (IN) students

\begin{tabular}{|l|c|c|c|}
\hline $\begin{array}{c}\text { Weight of improvement } \\
\text { importance } \\
\text { all Tuning competences }\end{array}$ & $\begin{array}{c}\text { OUT } \\
\text { students }\end{array}$ & $\begin{array}{c}\text { IN } \\
\text { students }\end{array}$ & $\begin{array}{c}\text { Reference weight } \\
\text { (all competences have equal } \\
\text { improvement importance) }\end{array}$ \\
\hline Instrumental & $41 \%$ & $42 \%$ & $33 \%$ \\
\hline Interpersonal & $22 \%$ & $24 \%$ & $27 \%$ \\
\hline Systemic competences & $37 \%$ & $34 \%$ & $40 \%$ \\
\hline
\end{tabular}

The greater impact of mobility on instrumental competences is even clearer if we look at the share in the above weights of the top twelve competences (Top12), as chosen by the OUT and IN samples respectively.

\section{Table 4}

Share of Top 12 competences in the weights corresponding to all 30 Tuning competences (see Table 3) for OUT and IN samples respectively

\begin{tabular}{|l|c|c|}
\hline \multicolumn{1}{|c|}{ Group of competences } & OUT & IN \\
\hline Instrumental & 0,85 & 0,89 \\
\hline Interpersonal & 0,78 & 0,70 \\
\hline Systemic competences & 0,63 & 0,61 \\
\hline
\end{tabular}


We clearly see that the share in the perceived weights of the three groups of competences definitely decreases when going from instrumental to interpersonal to systemic competences, a sign that the latter were better developed already at home: of course this is only true in general, since there are some noticeable and interesting exceptions. Indeed, some competences, which are most developed by exchange students, in terms of absolute value of importance of improvement, are not instrumental (see Table 2 above and for the numerical values see Table 5).

Looking at more detail, we see that, within the Top 12 competences:

- Instrumental competences - 5 competences are common to both samples: knowledge of a second language ( $2^{\text {nd }}$ in the OUT students' ordering and $1^{\text {st }}$ in the IN students' one), problem solving $\left(3^{\text {rd }}\right.$ and $\left.5^{\text {th }}\right)$, oral and written communication $\left(4^{\text {th }}\right.$ and $\left.4^{\text {th }}\right)$, capacity for organization and planning $\left(7^{\text {th }}\right.$ and $\left.10^{\text {th }}\right)$, decision-making $\left(10^{\text {th }}\right.$ and $\left.8^{\text {th }}\right)$. Moreover, IN students perceive as important: basic general knowledge $\left(20^{\text {th }}\right.$ in the OUT students' ordering and $11^{\text {th }}$ in the IN students' one, a surprising gap? See Table 8 below and related comments for a possible interpretation).

- Interpersonal competences - 3 competences are common to both samples: appreciation of diversity and multiculturality $\left(5^{\text {th }}\right.$ and $\left.6^{\text {th }}\right)$, ability to work in an international context $\left(9^{\text {th }}\right.$ and $\left.9^{\text {th }}\right)$, interpersonal skills $\left(8^{\text {th }}\right.$ and $\left.7^{\text {th }}\right)$. Moreover, OUT students show in addition: critical and self-critical abilities $\left(12^{\text {th }}\right.$ and $\left.16^{\text {th }}\right)$.

- Systemic competences - 2 competences are common to both samples: capacity to adapt to new situations $\left(1^{\text {st }}\right.$ and $\left.2^{\text {nd }}\right)$, understanding of cultures and customs of other countries $\left(6^{\text {th }}\right.$ and $\left.3^{\text {rd }}\right)$. Moreover, OUT students select capacity for applying knowledge in practice $\left(11^{\text {th }}\right.$ and $17^{\text {th }}$, quite a gap), while IN students select capacity to learn $\left(19^{\text {th }}\right.$ and $12^{\text {th }}$, quite a gap again!).

It is also instructive to look at the less ticked competences, i.e. those for which no relevant mobility impact occurs, or - better - is perceived. Let us focus on the last five. Three out of them are common to both samples. They are leadership, project design and management and elementary computing skills. Moreover, OUT students include in this less ticked group ethical commitment and ability to communicate with not experts, whereas IN students include concern for quality and ability to work in an interdisciplinary team. As we shall discuss below, an analysis by country subgroups of these competences gives a surprising new insight. 


\section{Comparison OUT versus IN students}

By analysing the numerical differences between outgoing and incoming students in the perceived importance of improvement (degree of improvement) of the several competences, we can extract further interesting information.

Moreover, it is convenient to keep in mind some reference values for the (renormalized) perceived importance of improvement, as they will become useful in the description of the results. If respondents had ticked all competences uniformly, then the importance value would be $16.7 \%$ for all competences (uniformity value or threshold, i.e. $500 \%$ divided by 30 ).

As to OUT students, their Top12 competences, i.e. the ones identified in the previous Section, are all and the only ones having an $\mathbf{I}_{\text {score }}$ above this value, with a maximum value equal to $69.2 \%$ for capacity to adapt to new situations. Below the uniformity value, we find a set of 13 competences, whose importance varies in the range $4 \%$ to $15 \%$ and finally a set of 5 less important competences, varying in importance between $0.9 \%$ and $4 \%$. A similar situation occurs for incoming students, whose Top12 set of competences (see again previous Section) shows a maximum $\mathbf{I}_{\text {score }}$ value equal to $61.3 \%$ for knowledge of a second language and includes two competences below (even though close to) the uniformity value, i.e. at $14.5 \%$ and $14.3 \%$. Then we find again a set of 13 competences, whose importance varies in the range $4 \%$ to $11.4 \%$ and finally 5 less important competences, varying in importance between $2.7 \%$ and $4 \%$. As a synthesis and for further reference, we give below the average values for the importance of improvement in the three above sets of competences, as found for the two main samples. They are quite similar.

\begin{tabular}{|l|c|c|}
\hline \multicolumn{1}{|c|}{ Reference values for improvement importance } & \multicolumn{2}{c|}{ Average importance value } \\
\hline \multicolumn{1}{|c|}{ Set of competences } & OUT & IN \\
\hline Top 12 competences & $31,4 \%$ & $31,2 \%$ \\
\hline Competences ranked 13 to 25 & $8,6 \%$ & $8,4 \%$ \\
\hline Competences ranked 26 to 30 (importance < 4\%) & $2,3 \%$ & $3,3 \%$ \\
\hline
\end{tabular}

Some general comments on the numerical values of the importance of improvement are worthwhile. They are complementary to the qualitative analysis made above, which relies on the simple order of importance. Table 5 below gives the actual $\mathbf{I}_{\text {score }}$ values for outgoing and incoming students. These two rankings show only two competences, whose importance of improvement 
value is above $60 \%$. The first one, which appears in both rankings, is knowledge of a second language, an instrumental competence, which is quite an obvious finding for a mobility programme; it will be discussed below in some detail in terms of country subgroups. The second is capacity to adapt to new situations, a systemic competence, at the top of OUT ranking and really characterizing an important feature for Italian young people, as discussed again below.

\section{Table 5}

Rankings (order of importance) of the Tuning competences for outgoing and incoming students, complete of the $\mathbf{I}_{\text {score }}$ value for each competence

\begin{tabular}{|l|c|}
\hline \multicolumn{1}{|c|}{ Tuning generic competences } & $\begin{array}{c}\text { Importance } \\
\text { (all OUT) }\end{array}$ \\
\hline Capacity to adapt to new situations & $69,2 \%$ \\
\hline Knowledge of a second language & $68,2 \%$ \\
\hline Problem solving & $31,0 \%$ \\
\hline Oral and written communication & $28,6 \%$ \\
\hline $\begin{array}{l}\text { Appreciation of diversity and } \\
\text { multiculturality }\end{array}$ & $27,2 \%$ \\
\hline $\begin{array}{l}\text { Understanding of cultures and } \\
\text { customs of other countries }\end{array}$ & $25,9 \%$ \\
\hline $\begin{array}{l}\text { Capacity for organization and } \\
\text { planning }\end{array}$ & $24,7 \%$ \\
\hline Interpersonal skills & $21,7 \%$ \\
\hline $\begin{array}{l}\text { Ability to work in an international } \\
\text { context }\end{array}$ & $21,1 \%$ \\
\hline Decision-making & $21,1 \%$ \\
\hline $\begin{array}{l}\text { Capacity for applying knowledge } \\
\text { in practice }\end{array}$ & $20,8 \%$ \\
\hline Critical and self-critical abilities & $17,2 \%$ \\
\hline Teamwork & $14,7 \%$ \\
\hline Research skills & $14,6 \%$ \\
\hline Information management skills & $12,7 \%$ \\
\hline $\begin{array}{l}\text { Capacity for generating new ideas } \\
\text { (creativity) }\end{array}$ & $10,1 \%$ \\
\hline Ability to work autonomously & $9,6 \%$ \\
\hline
\end{tabular}

\begin{tabular}{|l|c|}
\hline \multicolumn{1}{|c|}{ Tuning generic competences } & $\begin{array}{c}\text { Importance } \\
\text { (all IN) }\end{array}$ \\
\hline Knowledge of a second language & $61,3 \%$ \\
\hline Capacity to adapt to new situations & $45,5 \%$ \\
\hline $\begin{array}{l}\text { Understanding of cultures and } \\
\text { customs of other countries }\end{array}$ & $44,5 \%$ \\
\hline Oral and written communication & $35,1 \%$ \\
\hline Problem Solving & $34,3 \%$ \\
\hline $\begin{array}{l}\text { Appreciation of diversity and } \\
\text { multiculturality }\end{array}$ & $29,7 \%$ \\
\hline Interpersonal skills & $29,5 \%$ \\
\hline Decision-making & $24,9 \%$ \\
\hline $\begin{array}{l}\text { Ability to work in an international } \\
\text { context }\end{array}$ & $24,3 \%$ \\
\hline $\begin{array}{l}\text { Capacity for organization and } \\
\text { planning }\end{array}$ & $16,8 \%$ \\
\hline Basic general knowledge & $14,5 \%$ \\
\hline Capacity to learn & $14,3 \%$ \\
\hline Ability to work autonomously & $11,4 \%$ \\
\hline Capacity for analysis and synthesis & $10,8 \%$ \\
\hline Research skills & $10,6 \%$ \\
\hline Critical and self-critical abilities & $10,4 \%$ \\
\hline $\begin{array}{l}\text { Capacity for applying knowledge } \\
\text { in practice }\end{array}$ & $10,0 \%$ \\
\hline
\end{tabular}




\begin{tabular}{|l|c|}
\hline \multicolumn{1}{|c|}{ Tuning generic competences } & $\begin{array}{c}\text { Importance } \\
\text { (all OUT) }\end{array}$ \\
\hline Will to succeed & $9,3 \%$ \\
\hline Capacity to learn & $8,6 \%$ \\
\hline Basic general knowledge & $6,9 \%$ \\
\hline Concern for quality & $6,4 \%$ \\
\hline $\begin{array}{l}\text { Ability to work in an } \\
\text { interdisciplinary team }\end{array}$ & $5,1 \%$ \\
\hline $\begin{array}{l}\text { Grounding in basic knowledge of } \\
\text { the profession }\end{array}$ & $5,1 \%$ \\
\hline Capacity for analysis and synthesis & $4,7 \%$ \\
\hline Initiative and entrepreneurial spirit & $4,1 \%$ \\
\hline Leadership & $3,4 \%$ \\
\hline Project design and management & $2,8 \%$ \\
\hline Ethical commitment & $2,5 \%$ \\
\hline $\begin{array}{l}\text { Ability to communicate with not } \\
\text { experts }\end{array}$ & $1,6 \%$ \\
\hline Elementary computing skills & $0,9 \%$ \\
\hline Total & $500,0 \%$ \\
\hline
\end{tabular}

\begin{tabular}{|l|c|}
\hline \multicolumn{1}{|c|}{ Tuning generic competences } & $\begin{array}{c}\text { Importance } \\
\text { (all IN) }\end{array}$ \\
\hline Teamwork & $9,2 \%$ \\
\hline Initiative and entrepreneurial spirit & $8,9 \%$ \\
\hline Will to succeed & $8,5 \%$ \\
\hline $\begin{array}{l}\text { Ability to communicate with not } \\
\text { experts }\end{array}$ & $8,5 \%$ \\
\hline $\begin{array}{l}\text { Capacity for generating new ideas } \\
\text { (creativity) }\end{array}$ & $8,1 \%$ \\
\hline $\begin{array}{l}\text { Grounding in basic knowledge of } \\
\text { the profession }\end{array}$ & $4,6 \%$ \\
\hline Information management skills & $4,2 \%$ \\
\hline Ethical commitment & $4,0 \%$ \\
\hline Concern for quality & $3,7 \%$ \\
\hline Leadership & $3,7 \%$ \\
\hline $\begin{array}{l}\text { Ability to work in an } \\
\text { interdisciplinary team }\end{array}$ & $3,3 \%$ \\
\hline Project design and management & $3,1 \%$ \\
\hline Elementary computing skills & $2,7 \%$ \\
\hline Total & $500,0 \%$ \\
\hline
\end{tabular}

As to incoming students, capacity to adapt to new situations is ranked second, but only at a much lower value of importance (45.5\%) than the first one, together with understanding of cultures and customs of other countries (at $44.5 \%$ ), this latter competence being valued as low as $25.9 \%$ by the outgoing sample (again a large gap). Then we find two sets of competences (one per ranking) whose importance ranges between $35 \%$ and $24 \%$. The outgoing set includes five competences, i.e. problem solving, oral and written communication, appreciation of diversity and multiculturality, understanding of cultures and customs of other countries, capacity for organization and planning. The incoming set includes three competences, which are in a similar position and at similar value as in the outgoing sample, i.e. oral and written communication, problem solving, appreciation of diversity and multiculturality, plus three others, i.e. interpersonal skills, decision-making, ability to work in an international context. These latter three are ranked lower in the outgoing sample, but at a not too different importance value (around 21\%), together with capacity for applying knowledge in practice. 
The comparative analysis of the results mostly focuses on differences in the perceived importance of improvement for the all thirty Tuning competences.

\section{Table 6}

Importance of improvement for OUTgoing and INcoming Erasmus students at the University of Padova: renormalized values and their difference. Competences are ordered according decreasing difference (the actual order in importance of improvement in each sample is given in the first two columns. A yellow background means equal/almost equal position in the order)

\begin{tabular}{|c|c|l|c|c|c|}
\hline $\begin{array}{c}\text { OUT } \\
\text { order of } \\
\text { importance }\end{array}$ & $\begin{array}{c}\text { IN } \\
\text { order of } \\
\text { importance }\end{array}$ & \multicolumn{1}{|c|}{ Tuning generic competences } & $\begin{array}{c}\text { OUT } \\
\text { students }\end{array}$ & $\begin{array}{c}\text { IN } \\
\text { students }\end{array}$ & $\begin{array}{c}\text { Difference } \\
\text { (OUT } \\
\text { minus IN) }\end{array}$ \\
\hline 1 & 2 & Capacity to adapt to new situations & $69,2 \%$ & $45,5 \%$ & $23,8 \%$ \\
\hline 11 & 17 & Capacity for applying knowledge in practice & $20,8 \%$ & $10,0 \%$ & $10,8 \%$ \\
\hline 15 & 24 & Information management skills & $12,7 \%$ & $4,2 \%$ & $8,5 \%$ \\
\hline 7 & 10 & Capacity for organization and planning & $24,7 \%$ & $16,8 \%$ & $8,0 \%$ \\
\hline 2 & 1 & Knowledge of a second language & $68,2 \%$ & $61,3 \%$ & $6,9 \%$ \\
\hline 12 & 16 & Critical and self-critical abilities & $17,2 \%$ & $10,4 \%$ & $6,8 \%$ \\
\hline 13 & 18 & Teamwork & $14,7 \%$ & $9,2 \%$ & $5,5 \%$ \\
\hline 14 & 15 & Research skills & $14,6 \%$ & $10,6 \%$ & $4,0 \%$ \\
\hline 21 & 26 & Concern for quality & $6,4 \%$ & $3,7 \%$ & $2,7 \%$ \\
\hline 16 & 22 & Capacity for generating new ideas (creativity) & $10,1 \%$ & $8,1 \%$ & $2,0 \%$ \\
\hline 22 & 28 & Ability to work in an interdisciplinary team & $5,1 \%$ & $3,3 \%$ & $1,8 \%$ \\
\hline 18 & 20 & Will to succeed & $9,3 \%$ & $8,5 \%$ & $0,8 \%$ \\
\hline 23 & 23 & $\begin{array}{l}\text { Grounding in basic knowledge of the } \\
\text { profession }\end{array}$ & $5,1 \%$ & $4,6 \%$ & $0,5 \%$ \\
\hline 26 & 27 & Leadership & $3,4 \%$ & $3,7 \%$ & $-0,2 \%$ \\
\hline 27 & 29 & Project design and management & $2,8 \%$ & $3,1 \%$ & $-0,3 \%$ \\
\hline 28 & 25 & Ethical commitment & $4,0 \%$ & $-1,5 \%$ \\
\hline 30 & 30 & Elementary computing skills & $2,7 \%$ & $-1,76 \%$ \\
\hline 17 & 13 & Ability to work autonomously & $11,4 \%$ & $-1,76 \%$ \\
\hline 5 & 6 & Appreciation of diversity and multiculturality & $27,2 \%$ & $29,7 \%$ & $-2,5 \%$ \\
\hline 9 & 9 & Ability to work in an international context & $21,1 \%$ & $24,3 \%$ & $-3,2 \%$ \\
\hline 2 & 5 & Problem solving & $34,3 \%$ & $-3,3 \%$ \\
\hline
\end{tabular}




\begin{tabular}{|c|c|l|r|r|c|}
\hline $\begin{array}{c}\text { OUT } \\
\text { order of } \\
\text { importance }\end{array}$ & $\begin{array}{c}\text { IN } \\
\text { order of } \\
\text { importance }\end{array}$ & \multicolumn{1}{|c|}{ Tuning generic competences } & $\begin{array}{c}\text { OUT } \\
\text { students }\end{array}$ & $\begin{array}{c}\text { IN } \\
\text { students }\end{array}$ & $\begin{array}{c}\text { Difference } \\
\text { (OUT } \\
\text { minus IN) }\end{array}$ \\
\hline 10 & 8 & Decision-making & $21,1 \%$ & $24,9 \%$ & $-3,8 \%$ \\
\hline 25 & 19 & Initiative and entrepreneurial spirit & $4,1 \%$ & $8,9 \%$ & $-4,8 \%$ \\
\hline 19 & 12 & Capacity to learn & $8,6 \%$ & $14,3 \%$ & $-5,7 \%$ \\
\hline 24 & 14 & Capacity for analysis and synthesis & $4,7 \%$ & $10,8 \%$ & $-6,1 \%$ \\
\hline 4 & 4 & Oral and written communication & $28,6 \%$ & $35,1 \%$ & $-6,5 \%$ \\
\hline 29 & 21 & Ability to communicate with not experts & $1,6 \%$ & $8,5 \%$ & $-6,9 \%$ \\
\hline 20 & 11 & Basic general knowledge & $6,9 \%$ & $14,5 \%$ & $-7,6 \%$ \\
\hline 8 & 7 & Interpersonal skills & $21,7 \%$ & $29,5 \%$ & $-7,8 \%$ \\
\hline 6 & 3 & $\begin{array}{l}\text { Unders ta ndi ng of cul tures a nd cus toms of } \\
\text { other countries }\end{array}$ & $25,9 \%$ & $45,0 \%$ & $-19,0 \%$ \\
\hline
\end{tabular}

Table 6 shows this comparison for each competence, in decreasing order of the corresponding difference between OUT and IN students. Positive differences indicate that the importance of a competence was better improved for the OUT group of students and a negative difference for the IN group. The larger differences are at the top and at the bottom of Table 6, while in the middle of the Table we find the competences on which mobility has a similar impact for OUT as well as for IN students. In the difference range between $+3 \%$ and $-3 \%$ we find a dozen of competences: of which many have a low perceived improvement during mobility, but on the contrary two interpersonal ones show quite an appreciable importance of their improvement; these latter are:

\section{appreciation of diversity and multiculturality}

ability to work in an international context
(27.2\% in the OUT sample and $29.7 \%$ in the IN one)

( $21.1 \%$ and $24.3 \%$ respectively).

Again in this very group of competences, which shows a comparable mobility impact in the two samples, three other competences have a modest - but not vanishing - importance of improvement:

- Capacity for generating new ideas (creativity)

- Will to succeed

- Ability to work autonomously
$(10.1 \%$ in the OUT sample and $8.1 \%$ in the IN one) (9.3\% and $8.5 \%$ respectively) ( $9.6 \%$ and $11.4 \%$ respectively). 
We shall come back later on some of these competences, when describing country effects.

The largest differences between OUT and IN students in the importance of improvement of competences lend themselves to interesting comments. The largest positive difference occurs for capacity to adapt to new situations, being equal to as much as $23.8 \%(69.3 \%$ in the OUT sample and $45.5 \%$ in the IN one!). This may be explained easily. As it is well known, ${ }^{10}$ most Italian university students live with their families while studying. This is generally true also for Padova students. Thus, Erasmus is most often the first time when these students meet the challenges of a daily life without family support. In many other countries, as a general habit, students live away from the family when at the university. We anticipate here that the country subgroup "outgoing to PL" 11 perceive a 94\% importance of improvement for this competence (see Table 10a), an absolute maximum in this survey! On the contrary, among the incoming students only RO students shows an importance of improvement similar to the one perceived by Padova students, while AT, BE, PL, GR, UK and DE perceive the improvement of this competence at a much lower extent (between 33\% and 43\%).

The second most different perception about the improvement (i.e. the gap) between outgoing and incoming students regards capacity for applying knowledge in practice, which scores a difference of $10 \%$. This can be most profitably interpreted by grouping this competence together with four others, which show a similar gap, see Table 7 .

Do notice that all these competences ranked higher for the OUT students sample by 3 to 9 positions with respect to the IN students ranking positions and that all appeared within the first fifteen. According to facts and experiences, shared by the author with Italian and foreign colleagues during his long standing commitment in Erasmus exchanges, this gap in importance of improvement between OUT and IN students seems to reflect the Italian teaching-learning approach, which is quite systematic and analytical, but less pragmatic and not much addressed to concrete aspects of life and of job market.

${ }^{10}$ For instance, see Corriere Università, Sempre più "mammoni": Italiani fanalino $d^{\prime}$ Europa, February $9^{\text {th }}, 2015$, at http://www.corriereuniv.it/cms/20Ita15/02/giovani-italianipreferiscono-restare-casa-in-francia-uk-meta/; see also: Directorate General Education and Culture, Survey into the socio-economic background of Erasmus students (Brussels: European Commission, 2000), 13.

${ }^{11}$ Here and in the following, we use the same country abbreviations as those used in the web. 


\section{Table 7}

Competences which are better improved by outgoing students. The first column shows the difference in importance between the two groups (OUT minus IN).

The two last columns show the actual $\mathbf{I}_{\text {score }}$ value for the importance of improvement in the two samples. Rounded values

\begin{tabular}{|l|c|c|c|}
\hline \multicolumn{1}{|c|}{ Competence } & Gap & OUT & IN \\
\hline Capacity for applying knowledge in practice & $11 \%$ & $21 \%$ & $10 \%$ \\
\hline Capacity for organization and planning & $9 \%$ & $24 \%$ & $15 \%$ \\
\hline $\begin{array}{l}\text { Information management skills (ability to retrieve } \\
\text { and analyze information from different sources) }\end{array}$ & $9 \%$ & $12 \%$ & $4 \%$ \\
\hline Critical and self-critical abilities & $8 \%$ & $17 \%$ & $9 \%$ \\
\hline Team-work & $6 \%$ & $14 \%$ & $8 \%$ \\
\hline
\end{tabular}

On the other hand, another group of competences reveals a quite complementary aspect, thus confirming the above interpretation. Table 8 indicates that the Italian teaching-learning approach is perceived by IN students as being more systematic and as offering deeper insight, in such a way that it promotes a better capacity to learn. Please note that capacity to learn and basic general knowledge (as well as capacity for analysis and synthesis even though at a lesser extent) ranked high in the order of importance of incoming students. Indeed, capacity to learn shows an importance of improvement among UK students which is as high as $21 \%$, followed by ES and BE students (19\%), quite above the value for the incoming students whole sample (i.e. 14\%).

\section{Table 8}

Competences which are better improved by incoming students. The first column shows the difference in importance between the two samples of students

(OUT minus IN). The two last columns show the actual $\mathbf{I}_{\text {score }}$ value for the importance of improvement in the two samples. Rounded values

\begin{tabular}{|l|c|c|c|}
\hline \multicolumn{1}{|c|}{ Competence } & Gap & OUT & IN \\
\hline Capacity for analysis and synthesis & $-6 \%$ & $5 \%$ & $11 \%$ \\
\hline Basic general knowledge & $-7 \%$ & $7 \%$ & $14 \%$ \\
\hline Capacity to learn & $-6 \%$ & $9 \%$ & $14 \%$ \\
\hline
\end{tabular}

The competence understanding of cultures and customs of other countries records the largest negative difference between the OUT and IN samples, i.e. 
$-18.7 \%(25,9 \%$ absolute value in the OUT sample and $44,5 \%$ in the IN one). It seems that Italian culture and customs are perceived as being quite diverse from those pertaining to incoming students and - in addition - it seems that the stay in Padova quite helped in understanding this diversity. Interestingly, among guest students there is a further difference of importance of improvement $(-18 \%)$ between students from Southern countries (ES, GR, PT, RO, HR) and students from Northern countries (AT, BE, UK, PL, DE, FR). The latter group perceives an importance of improvement as high as $53 \%$. This corresponds to a large gap between the entire outgoing sample and this group equal to $-27 \%$. Such a gap could be interpreted in several ways, but conclusive statements need more investigation. Possible interpretations for the low importance of improvement perceived by outgoing students for understanding of cultures and customs of other countries are: i) a better general and cultural preparation of the outgoing students at secondary school level (i.e. a competence already developed at home). ii) lack of interest in the outgoing students for the culture of the visited country, focusing on academic achievements only, under the pressure to acquire credits. This might very well be the case of the subgroup outgoing to DK, a highly selected subgroup of students, mostly visiting Danmarks Tekniske Universitet (DTU in Lingby, Copenhagen) within the T.I.M.E. network: ${ }^{12}$ indeed, this subgroup score only $13 \%$ importance of improvement. iii) narrow-mindedness and provincialism of outgoing students, perhaps also affected by prejudices. iv) too many efforts taken in other directions, e.g. to adapt to new situations. On the other end, a possible interpretation for the high score of this competence among incoming students might lie in the persisting romantic myth of "traveling to Italy is beautiful".

The achievements in the competence we just discussed may be compared to the achievements in the already mentioned appreciation of diversity and multiculturality (21.1\% absolute $\mathbf{I}_{\text {score }}$ value in the OUT sample and $24.3 \%$ in the IN one). Indeed, this competence shows only $-2.5 \%$ difference between outgoing and incoming students. This might be an interesting fact in itself. Nevertheless, this result is the combined result of many country subgroups, each one behaving rather differently. Among outgoing students this competence finds relevant importance of improvement in students going to TR (39\%, a reasonable result!), followed by those going to $\mathrm{CH}, \mathrm{BE}$ and $\mathrm{SE}(32.4 \%, 31.5 \%$ and $30.9 \%$ respectively). The less affected subgroups are those going to $\mathrm{CZ}$ (only 10\% importance of improvement), SF and DK (17\%), PL (20\%). Among

${ }_{12}$ T.I.M.E. - Top Industrial Managers for Europe, a quality engineering network since 1989, see https://www.time-association.org/ 
incoming students those perceiving significant improvement are BE, GR and FR students $(58 \%, 40 \%$ and $39 \%$ respectively); surprisingly the UK students declare only $21 \%$ importance of improvement (this is the lowest value found; however, this should be compared with the value $62 \%$ in the previously discussed competence). This may hint that UK students already experience a challenging multicultural environment at home. We shall further discuss below these two competences in Section IV.1.

Table 6 shows that the competence interpersonal skills shows a $-7.8 \%$ difference, being the second, though not as marked as the first, largest negative difference between the OUT and IN samples (absolute $\mathbf{I}_{\text {score }}$ values are $21.7 \%$ and $29.5 \%$ respectively). This seems to indicate that Italian daily environment (university life included) helps in developing interpersonal relationships and communication skills. Students from DE and PT, while in Padova, perceive for this competence an importance of improvement as high as $51 \%$ and $38 \%$ respectively, i.e. values quite higher than the value yielded by the entire incoming sample. As to outgoing students, they perceive an importance of improvement for this competence, which is very similar for students visiting ES, DE and FR (equal or slightly larger than the value found for the whole outgoing sample). The $\mathbf{I}_{\text {score }}$ value raises for those visiting the UK (26\%), BE (32\%) and NO (39\%), but in DK, NL, SE and SF it is below the value pertaining to the whole outgoing sample.

\section{Country effects in more detail}

The two main samples can be divided into their country subgroups by splitting according to the visited country (outgoing sample) or according to the home country (incoming sample). Table $9 \mathrm{a}$ and $9 \mathrm{~b}$ show relevant details. We consider only those countries, which involve at least 14 students. In this manner, the resulting country subgroups cover respectively the $95 \%$ and the $87 \%$ of the entire outgoing and incoming samples. Ranked in terms of the numbers of students, the most visited countries are ES, DE, FR, UK, PT and BE and the countries which sent most students to Padova are ES, DE, UK, FR, PL and PT.

We describe a number of interesting cases below, which show the richness of facts and possible interpretations related to country effects; however, further investigation is needed to confirm some conclusions. Moreover, the reader should be aware that for some country subgroups the given percentage importance relies on a small number of students. Thus random fluctuations in the results may very well occur. In some cases, this fact might weaken our interpretations. 


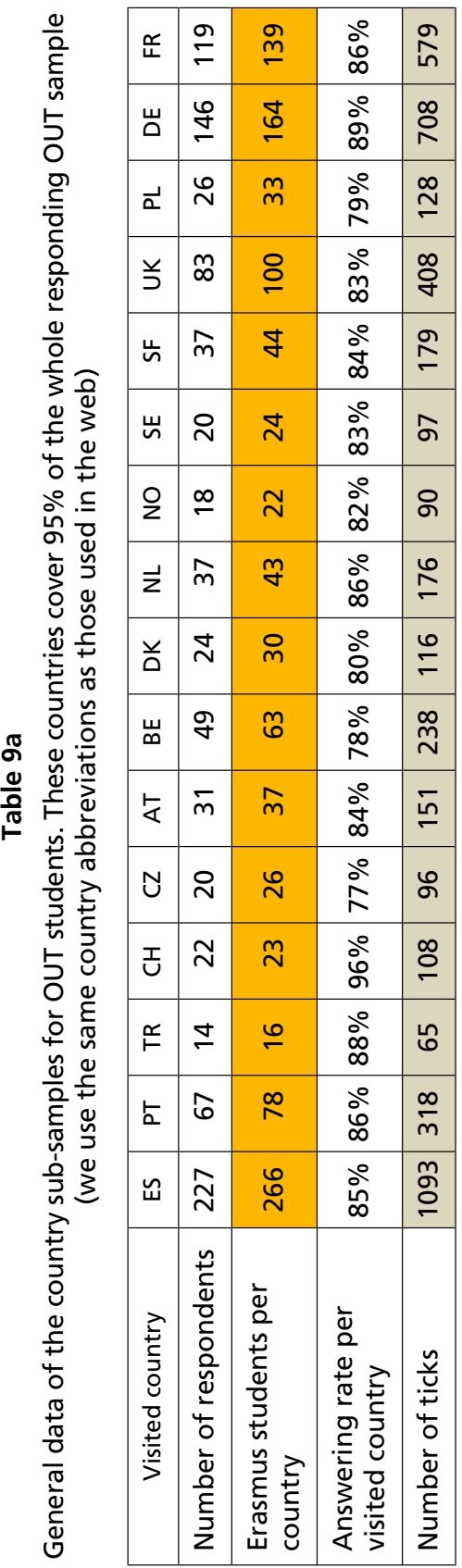

\begin{tabular}{|c|c|c|c|c|c|}
\hline$\frac{0}{\frac{0}{g}}$ & 弚 & $\tilde{m}$ & $\stackrel{\leftrightarrow}{\forall}$ & 웅 & $\stackrel{\text { ก }}{\leftarrow}$ \\
\hline 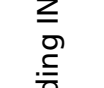 & ○ & $\stackrel{m}{N}$ & $\stackrel{\llcorner}{\sim}$ & ふั & $\infty$ \\
\hline$\frac{\overline{0}}{0}$ & 占 & $\bar{m}$ & $\stackrel{\bullet}{m}$ & 犬̊̊ & $\stackrel{\circ}{m}$ \\
\hline 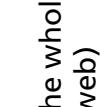 & $\vec{a}$ & 우 & ร & ㅇํㅁ & $\stackrel{m}{\infty}$ \\
\hline 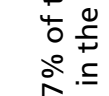 & 号 & 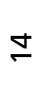 & 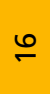 & $\begin{array}{l}\stackrel{0}{\infty} \\
\infty\end{array}$ & ถิ \\
\hline 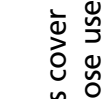 & 寽 & $\stackrel{\infty}{-}$ & $\stackrel{\infty}{\infty}$ & $\begin{array}{l}\circ \\
\text { 음 }\end{array}$ & $\stackrel{\text { L }}{\wedge}$ \\
\hline & 采 & $\stackrel{m}{m}$ & $\hat{m}$ & ふें & ผั \\
\hline 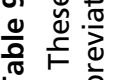 & Щّ & $\stackrel{\infty}{=}$ & ్ํำ & 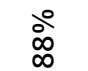 & $\stackrel{0}{N}$ \\
\hline & 㟔 & 으 & $\stackrel{\text { ㅁ }}{=}$ & ஃ̊ & $\stackrel{\text { N }}{\stackrel{\gamma}{\sigma}}$ \\
\hline 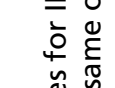 & 岗 & $\stackrel{\Xi}{\sim}$ & 이 & ○ें & ঠ \\
\hline 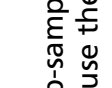 & 安 & $\underline{\bullet}$ & $\approx$ & $\stackrel{\circ}{\text { ळ̆ }}$ & $\stackrel{0}{N}$ \\
\hline 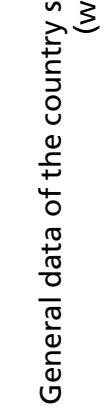 & 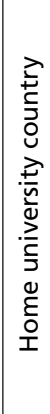 & 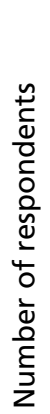 & 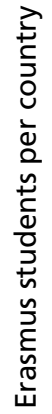 & 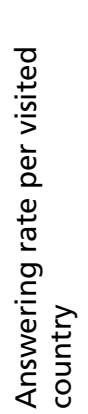 & 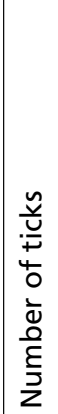 \\
\hline
\end{tabular}


We can look at the importance of improvement perceived by the country subgroups during their mobility experience from different points of view, i.e.:

- Focusing on a given competence in order to detect differences in their improvement linked to the home country (incoming students) or to the guest country (outgoing students). In some cases, this was already described above.

- Looking at a given country subgroup, either outgoing or incoming, in order to see which competences have resulted in the largest importance of improvement for its students.

- Looking at the exchange of competences which occurs between students, belonging to a given pair of countries, i.e. between the subgroups "students outgoing to a given country" and "students incoming from that same country". We shall refer to them as "paired" country subgroups.

\section{IV.1. From the point of view of a given competence}

We consider knowledge of a second language, which is ranked high for both OUT and IN students as an example of this first point of view. We note that the difference in $\mathbf{I}_{\text {score }}$ between the OUT and IN samples is relatively small (i.e. $7 \%$ ) compared to their actual values $(68,2 \%$ and $61,3 \%$ respectively). In general terms, outgoing students seem to benefit a bit more from the mobility experience, thus showing that Padova students are in general less equipped with foreign language capabilities. However, country effects tell something more. As detailed below in Table 10a and 10b, many country subgroups perceive an $\mathbf{I}_{\text {score }}$ regarding knowledge of a second language, which is higher than $70 \%$. Among outgoing students, those going to $\mathrm{CH}$ (mostly to French speaking universities) perceive an $\mathbf{I}_{\text {score }}$ value which is $20 \%$ (!) higher than the value yielded by the entire outgoing sample. This might show that the French language preparation was limited and that the improvement was quite substantial. Students going to CZ, NL, TR, SE perceive an $\mathbf{I}_{\text {score }}$ value, which is 11 to $9 \%$ higher than the one perceived by the entire outgoing sample; here it is not clear whether they refer to the language of that country (which is most probably the case) or to English as lingua franca. Students going to FR and DE perceive an $\mathbf{I}_{\text {score }}$ close to (a bit lower than) the one perceived by the entire OUT sample. Finally, the students going to UK also perceive an $\mathbf{I}_{\text {score }}$ value which is $8 \%$ lower than the value perceived by the entire OUT sample, and score the minimum value among 
large country subgroups; this is a clear hint to the fact that the language preparation was already good at arrival time and thus "not much" improvement was needed. Among incoming students, the second language is Italian without any doubt. The largest improvement is perceived by AT students (92\% importance of improvement), followed by GR, PL, BE and DE students with respectively $80 \%, 74 \%, 72 \%$ and $67 \%$. Latin countries range from $50 \%$ (PT students) to $62 \%$ (ES students) with RO and FR students at $57 \%$ and $58 \%$ respectively. UK students perceive an $\mathbf{I}_{\text {score }}$ value equal to $59 \%$, i.e. slightly below the value yielded by the entire incoming sample. This fact might hint at either the fact that their preparation was already reasonable at arrival $~^{13}$ or that they did not find it useful to learn the Italian language well, since English is a kind of lingua franca among European young people.

Tables 10a and 10b, regarding outgoing and incoming students respectively, summarize for each competences those country subgroups, which show the largest improvement. The tables also give, for reference purposes, the $\mathbf{I}_{\text {score }}$ of each competence for the entire corresponding sample, (i.e. OUT or IN sample).

\section{Table 10a}

Importance of improvement for all outgoing students and for best improving country subgroups

\begin{tabular}{|l|c|l|}
\hline \multicolumn{1}{|c|}{ Tuning competence } & $\begin{array}{c}\text { OUT } \\
\text { importance } \\
\text { (all OUT) }\end{array}$ & \multicolumn{1}{|c|}{ Outgoing country groups experiencing major impact } \\
\hline Capacity to adapt to new situations & $69,2 \%$ & PL (94\%), DK (82\%), CH \& UK (74\%), CZ \& AT (73\%) \\
\hline Knowledge of a second language & $68,2 \%$ & CH (88\%), CZ (78\%), SE\& TR \& NL (77\%) \\
\hline Problem solving & $31,0 \%$ & TR (46\%), SF (42\%), NL (40\%) \\
\hline Oral and written communication & $28,6 \%$ & SE (36\%), PT (35\%), UK (33\%) \\
\hline Appreciation of diversity and multiculturality & $27,2 \%$ & TR (38\%), CH \& BE (32\%) \\
\hline $\begin{array}{l}\text { Understanding of cultures and customs of } \\
\text { other countries }\end{array}$ & $25,9 \%$ & SF \& SE (32\%), TR (31\%) \\
\hline Capacity for organization and planning & $24,7 \%$ & NO (39\%), BE (38\%), AT (36\%) \\
\hline Interpersonal skills & $21,7 \%$ & NO (39\%), BE (32\%) \\
\hline Decision-making & $21,1 \%$ & NO (33\%), SE (31\%), PL(27\%) \\
\hline Ability to work in an international context & $21,1 \%$ & CH (42\%), DK (30\%) \\
\hline Capacity for applying knowledge in practice & $20,8 \%$ & BE (36\%), NO (33\%), CZ \& NL (26\%) \\
\hline
\end{tabular}

${ }^{13}$ In the author's experience as Erasmus coordinator, it happened to see UK students giving up their stay in Italy, because they were not successful at the examination in Italian language at their own university 


\begin{tabular}{|l|c|l|}
\hline \multicolumn{1}{|c|}{ Tuning competence } & $\begin{array}{c}\text { OUT } \\
\text { importance } \\
\text { (all OUT) }\end{array}$ & \multicolumn{1}{|c|}{ Outgoing country groups experiencing major impact } \\
\hline Critical and self-critical abilities & $17,2 \%$ & NO (28\%), UK 27\%), PL (23\%) \\
\hline Teamwork & $14,7 \%$ & DK (26\%), CZ (21\%), PL (20\%) \\
\hline Research skills & $14,6 \%$ & PL (27\%), AT (26\%), NL (23\%), SF (22\%) \\
\hline Information management skills & $12,7 \%$ & TR (23\%),DK (17\%), many countries (16\%) \\
\hline Capacity for generating new ideas (creativity) & $10,1 \%$ & TR (23\%), CZ (16\%) \\
\hline Ability to work autonomously & $9,6 \%$ & NO (39\%), TR (23\%), CH (14\%) \\
\hline Will to succeed & $9,3 \%$ & CZ (21\%), TR (15\%), DK \& AT (13\%) \\
\hline Capacity to learn & $8,6 \%$ & AT (17\%), FR \& BE (13\%) \\
\hline Basic general knowledge & $6,9 \%$ & SE (15\%), NO (11\%) \\
\hline Concern for quality & $6,4 \%$ & FR (13\%), BE (11\%) \\
\hline $\begin{array}{l}\text { Grounding in basic knowledge of the } \\
\text { profession }\end{array}$ & $5,1 \%$ & SE (15\%), UK (9\%) \\
\hline Ability to work in an interdisciplinary team & $5,1 \%$ & DK (13\%), PL (12\%), BE (11\%) \\
\hline Capacity for analysis and synthesis & $4,7 \%$ & NO (11\%), CZ (10\%) \\
\hline Initiative and entrepreneurial spirit & $4,1 \%$ & CH \& DK (9\%) \\
\hline Leadership & $3,4 \%$ & DK (26\%), many countries (0\%) \\
\hline Project design and management & $2,8 \%$ & DK (13\%), CZ (10\%), many countries (0\%) \\
\hline Ethical commitment & $2,5 \%$ & CZ (16\%), CH (9\%), SF (6\%) \\
\hline Ability to communicate with not experts & $1,6 \%$ & DK (9\%), TR (8\%), many countries (0\%) \\
\hline Elementary computing skills & $0,9 \%$ & NO (6\%), CH (5\%), many countries (0\%) \\
\hline
\end{tabular}

\section{Table 10b}

\section{Importance of improvement for all incoming students and for best improving country subgroups}

\begin{tabular}{|l|c|l|}
\hline \multicolumn{1}{|c|}{ Tuning competence } & $\begin{array}{c}\text { IN } \\
\text { importance } \\
\text { (all IN) }\end{array}$ & \multicolumn{1}{|c|}{ Incoming country groups experimenting major impact } \\
\hline Knowledge of a second language & $61,3 \%$ & AT (92\%), GR (80\%), PL 74 \%), BE (72\%) \\
\hline Capacity to adapt to new situations & $45,5 \%$ & RO (69\%), HR (61\%), FR (55\%), ES (49\%) \\
\hline $\begin{array}{l}\text { Understanding of cultures and customs of } \\
\text { other countries }\end{array}$ & $44,5 \%$ & AT (72\%), UK (62\%), HR (61\%), DE (55\%) \\
\hline Oral and written communication & $35,1 \%$ & HR (79\%), BE \& UK (48\%), AT (46\%), PL (41\%) \\
\hline Problem solving & $34,3 \%$ & PT (50\%), ES \& RO \& GR (40\%) \\
\hline Appreciation of diversity and multiculturality & $29,7 \%$ & BE (58\%), GR (40\%), AT \& FR (39\%) \\
\hline Interpersonal skills & $29,5 \%$ & DE (51\%), PT (38\%), PL (33\%) \\
\hline
\end{tabular}




\begin{tabular}{|l|c|l|}
\hline \multicolumn{1}{|c|}{ Tuning competence } & $\begin{array}{c}\text { IN } \\
\text { importance } \\
\text { (all IN) }\end{array}$ & \multicolumn{1}{|l|}{ Incoming country groups experimenting major impact } \\
\hline Decision-making & $24,9 \%$ & FR (36\%), PT (35\%), RO (34\%), ES (31\%) \\
\hline Ability to work in an international context & $24,3 \%$ & UK \& PL (41\%), RO (40\%), AT (39\%), PT (38\%) \\
\hline Capacity for organization and planning & $16,8 \%$ & GR (33\%), AT (26\%), DE (20\%) \\
\hline Basic general knowledge & $14,5 \%$ & AT (20\%), RO (17\%) \\
\hline Capacity to learn & $14,3 \%$ & UK (21\%), ES \& BE (19\%) \\
\hline Ability to work autonomously & $11,4 \%$ & BE (29\%), UK (24\%), HR (18\%), FR (16\%) \\
\hline Capacity for analysis and synthesis & $10,8 \%$ & RO (23\%), ES (16\%), BE (14\%), FR (13\%) \\
\hline Research skills & $10,6 \%$ & GR (27\%), PT (23\%), UK (21\%), AT (20\%) \\
\hline Critical and self-critical abilities & $10,4 \%$ & GR (20\%), RO (17\%) \\
\hline Capacity for applying knowledge in practice & $10,0 \%$ & UK (14\%), AT \& GR (13\%) \\
\hline Teamwork & $9,2 \%$ & PL (19\%) \\
\hline Initiative and entrepreneurial spirit & $8,9 \%$ & ES (23\%), PT (12 \%), many countries (0\%) \\
\hline Ability to communicate with not experts & $8,5 \%$ & DE \& RO (11\%), BE \& UK \% FR (10\%) \\
\hline Will to succeed & $8,5 \%$ & UK (21\%), FR (19\%) \\
\hline Capacity for generating new ideas (creativity) & $8,1 \%$ & HR (26\%), GR (20\%), BE (14\%) \\
\hline $\begin{array}{l}\text { Grounding in basic knowledge of the } \\
\text { profession }\end{array}$ & $4,6 \%$ & ES (6\%), many countries (0\%) \\
\hline Information management skills & $4,2 \%$ & PT (8\%), GR \& AT (7\%) \\
\hline Ethical commitment & $4,0 \%$ & PT (8\%), DE \& GR (7\%) \\
\hline Leadership & $3,7 \%$ & RO (6\%), BE (5\%), many countries (0\%) \\
\hline Concern for quality & $3,7 \%$ & AT (13\%), UK (10\%), many countries (0\%) \\
\hline Ability to work in an interdisciplinary team & $3,3 \%$ & RO (6\%), DE (5\%), many countries (0\%) \\
\hline Project design and management & $3,1 \%$ & GR (7\%), many countries (0\%) \\
\hline Elementary computing skills & $2,7 \%$ & HR (9\%), GR (7\%), RO (6\%), many countries (0\%) \\
\hline
\end{tabular}

A general finding is that practically all listed competences have some country subgroups, which perceive values, for their importance of improvement, higher or even much higher than the value of the corresponding main sample (either OUT or IN). In other words, we see relevant fluctuations in the perceived importance among the several country subgroups. In some cases competences with a low $\mathbf{I}_{\text {score }}$ in the entire main sample (either OUT or IN) receive an appreciable number of ticks in some of their country subgroups. These, sometimes strong, fluctuations may be related to a number of factors, linked to both the academic and the ordinary life environments experienced by the given subgroup. In this way, a diversified and rich set of possible interpretations can be assembled. To illustrate this point, we list some stimulating examples starting with outgoing students. 


\section{Outgoing subgroups}

For each listed competence, between parentheses we give the $\mathbf{I}_{\text {score }}$ value for the importance of improvement perceived by the entire outgoing sample: ${ }^{14}$

- Problem solving ( $\mathbf{I}_{\text {score }}=34.3 \%$ for the entire OUT sample): the most improving student subgroups are those going to countries with "difficult" languages;

- Understanding of cultures and customs of other countries (25,9\%): the most improving subgroups are those going to Scandinavian countries (where SF and SE are perceived as really challenging, but still score an importance value lower than the one achieved by the entire incoming sample, see below) and to TR. The decoupling which occurs between the improvement of this competence and the one regarding appreciation of diversity and multiculturality is also of interest. Indeed, while the $\mathbf{I}_{\text {score }}$ values for the importance of improvement of these two competences are similar in the entire OUT sample (25.9\% and $27.2 \%$ respectively), some country subgroups show quite different values in their corresponding $\mathbf{I}_{\text {score }}$ values;

- Ability to work autonomously (9.6\%): students going to NO and TR perceive quite a large importance of improvement (39\% and 23\%). The case of this NO subgroup shows the largest positive difference with respect to the $\mathbf{I}_{\text {score }}$ value for the entire IN sample among all possible subgroups. These high importance values may be related to students, who for some reasons had to work alone (e.g. information retrieval at a computer, which in this NO subgroup is $9 \%$ above the overall value!); thesis work should be excluded since the improvement in research skills is quite below its overall value for these subgroups.

- Grounding in basic knowledge of the profession (5.1\%): students going to SE perceive a $15 \%$ importance of improvement and those going to UK a 9\% importance. The SE-going students are a highly selected subgroup mostly visiting Kungliga Tekniska Högskolan (Royal Institute of Technology) within the already quoted T.I.M.E. network. The UK data are most probably linked to the pragmatic UK academic environment, quite open to the job market needs. It is also worth noting that many subgroups perceive $\mathbf{I}_{\text {score }}=0 \%$ for this competence.

${ }^{14}$ In this and in the following lists of competences, we specify for each competence between parentheses its $\mathbf{I}_{\text {score }}$ value for the main sample under consideration (either OUT or IN sample), repeating its full explanation only in the first item of each list. 
- Leadership (3.4\%): students going to DK perceive a $26 \%$ importance of improvement (many other country subgroups perceive $\mathbf{I}_{\text {score }}=0 \%$ !). The DK-going students are again a highly selected subgroup mostly visiting Danmarks Tekniske Universitet (DTU in Lingby), within the already quoted T.I.M.E. network.

- Project design and management (2.8\%): again students going to DK perceive $13 \%$ improvement importance (and many other country subgroups perceive $0 \%$ !).

- Ethical commitment (2.5\%): students going to $\mathrm{CZ}$ perceive $16 \%$ importance of improvement and those going to $\mathrm{CH}$ a $9 \%$ importance. As to students going to $\mathrm{CZ}$, this somewhat unusual result can be traced to 3 students visiting Charles University in the life sciences area. However, these numbers are really too small, to be conclusive!

\section{Incoming subgroups}

For each listed competence, between parentheses we give the $\mathbf{I}_{\text {score }}$ value for the importance of improvement perceived by the entire incoming sample:

- Problem solving $\left(\mathbf{I}_{\text {score }}=34.3 \%\right.$ for the entire IN sample): most improving students subgroups are those coming from southern countries.

- Understanding of cultures and customs of other countries (44.5\%): a significant aspect is that the largest increase occurs in the DE and UK subgroups. Moreover, as compared to outgoing students, the improvement of this competence is perceived as more important than the improvement in appreciation of diversity and multiculturality $(25,9 \%$, see below). Again, such an enhanced importance is quite pronounced in larger country subgroups (UK and DE incoming students show respectively an enhancement (i.e. difference between the two corresponding $\mathbf{I}_{\text {score }}$ values) equal to $41.4 \%$ and $23.2 \%$; ES students show a $13 \%$ enhancement, while FR students only 3.2\%). Such facts confirm that these two competences are really unrelated in the students' perception. A possible interpretation is that students incoming to Padova find a really welcoming and receptive environment (e.g. through the activities of the local branch of Erasmus Student Network or thanks to the integration efforts of the University Language Centre), which helps them to enter the Italian way of life and culture (customs). On the other hand, these data seem to show that these same students 
have a home environment rich in diversity and multiculturality. By further looking at the data for understanding of cultures and customs of other countries, we can find some finer country effects, probably linked to local situations. ${ }^{15}$

- Appreciation of diversity and multiculturality (25,9\%): most improving subgroups are those coming from AT, UK, HR and DE; this result is further highlighted below in terms of a comparison between Northern and Southern incoming students.

- Will to succeed (8.5\%): UK and FR students indicate respectively $21 \%$ and 19\% importance of improvement, covering about one fourth of the students who select this competence. Half of the students "willing to succeed" belong to humanities and economics and one fourth to political sciences and psychology. This may indicate a competitive environment found by these students in Padova.

- Ethical commitment (4\%) shows small oscillations, between 0 and $7 \%$ (PT, DE and GR students, respectively at $7.7 \%, 7.4 \%$ and $6.7 \%$ ). It is interesting to note that $29 \%$ of the students who select this competence as an important one are from the area of economics.

- Concern for quality (3.7\%) shows larger oscillations in importance: four cases of no ticks are counterbalanced by $13 \%$ of the AT subgroup and $10 \%$ of the UK students.

\section{IV.2. From the point of view of a given country subgroup}

Outgoing students

The profile of the outgoing country subgroups, in terms both of most improved competences and of actual values for importance of improvement, can be quite different from the one pertaining to the entire outgoing sample. Two aspects are relevant here. The largest country subgroups, ES and DE, show small deviations from the entire OUT sample profile. Quite different profiles pertain to smaller country subgroups. We already remarked on the peculiarity of

${ }_{15}$ As an example, RO guest students declare an importance of improvement as low as $11 \%$, this low percentage being possibly related to a large Romanian community living in Padova, which may then act as a cultural mediator. A further example is offered by BE students, who declare $38 \%$, i.e. quite below the $\mathbf{I}_{\text {score }}$ value of the Northern grouping, this fact being possibly linked to the existence of a strong Italian immigration in Belgium in the middle of last century. And so on. 
the subgroups outgoing to DK and SE. Table 11a, which complements Table $10 \mathrm{a}$, confirms such aspects by listing for several country subgroups the number of competences, for which the importance of improvement achieved is either the first or a second maximum value. Scandinavian countries (SE, SF, NO, DK) collect 17 out of 30 absolute maxima, but if we consider the merged "Scandinavian sample", the importance of improvement values are usually quite close to the values for the entire sample.

\section{Table 11a}

Outgoing students' country subgroups: number of competences for which maximum and second maximum improvement occurred

\begin{tabular}{|l|c|c|c|c|c|c|c|c|c|c|c|c|c|c|c|c|}
\hline \multicolumn{1}{|c|}{ Country } & ES & PT & TR & CH & CZ & AT & BE & DK & NL & NO & SE & SF & UK & PL & DE & FR \\
\hline $\begin{array}{l}\text { Number of } \\
\text { Max }\end{array}$ & 0 & 0 & 3 & 3 & 2 & 1 & 1 & 5 & 0 & 8 & 3 & 1 & 0 & 2 & 0 & 1 \\
\hline $\begin{array}{l}\text { Number of } \\
2^{\text {nd }} \text { Max }\end{array}$ & 0 & 1 & 3 & 2 & 5 & 1 & 3 & 4 & 0 & 2 & 2 & 2 & 2 & 1 & 1 & 1 \\
\hline Sum & 0 & 1 & 6 & 5 & 7 & 2 & 4 & 9 & 0 & 10 & 5 & 3 & 2 & 3 & 1 & 2 \\
\hline
\end{tabular}

Some further comments are devoted to those competences, which are affected by mobility in a limited way, but which, nevertheless, show clear country effects:

- Competence will to succeed $\left(\mathbf{I}_{\text {score }}=9.3 \%\right.$ for the entire OUT sample): students visiting $\mathrm{CZ}$ and TR indicate respectively $21 \%$ and $15 \%$ importance of improvement; students going to ES, AT, DK, SF and UK perceive an importance (between 11\% and 13\%), which is higher than the whole sample value.

- Competence ethical commitment (2.5\%) shows large oscillations, between 0 and $16 \%$. Students going to $\mathrm{CZ}$ perceive a $16 \%$ importance of improvement, which exceeds that of students going to $\mathrm{CH}(9 \%)$ and all the others. It seems like in $\mathrm{CZ}$ as well as in $\mathrm{CH}$ (to a lesser extent, though) ethical issues are embedded in ordinary/academic life more deeply than elsewhere.

$\underline{\text { Incoming students }}$

Among incoming students, some country subgroups show a profile of the perceived importance of improvement among the 30 competences, which is 
rather different from the one of the entire sample. UK students offer a clear example. They rank first understanding of cultures and customs of other countries $\left(\mathbf{I}_{\text {score }}=62 \%\right)$, followed by knowledge of a second language (59\%), oral and written communication (48\%) and by capacity to adapt to new situations and ability to work in an international context (both at $41 \%$, but respectively below and quite above the value for the whole sample!). The perceived improvement in ability to work autonomously (24\%, the second highest - after BE students - among all country subgroups!) is worth a particular comment. It may be related to the fact ${ }^{16}$ that the study progression in UK universities is often accompanied by the institution (e.g. through advising tutors) and not left to the student's personal initiative, as it is the case - for example - in Italy. A complementary confirmation to this comment is in the importance of improvement for ability to work autonomously perceived by the whole outgoing sample (only 9.6\%) and, within it, by the subgroup of Padova students going to UK (7.4\%, see also below). When compared to all other country subgroups, UK students coming to Padova show a maximum of importance of improvement in four competences (capacity for applying knowledge in practice, capacity to learn, ability to work in an international context, will to succeed). Furthermore, they show a second maximum in five competences (oral and written communication, teamwork, understanding of cultures and customs of other countries, ability to work autonomously, concern for quality). Such a rewarding profile is not common among the country subgroups; see synthetic details in Table 11b, which complements Tables 10b from the point of view of the home country.

\section{Table 11b}

Incoming students' country subgroups: number of competences for which maximum and second maximum improvement occurred

\begin{tabular}{|l|c|c|c|c|c|c|c|c|c|c|c|}
\hline \multicolumn{1}{|c|}{ COUNTRY } & ES & GR & PT & RO & AT & BE & UK & PL & DE & FR & HR \\
\hline Number of Max & 2 & 4 & 3 & 5 & 4 & 2 & 4 & 1 & 1 & 1 & 3 \\
\hline Number of $2^{\text {nd }}$ Max & 3 & 6 & 4 & 2 & 1 & 2 & 5 & 1 & 3 & 2 & 1 \\
\hline Sum & 5 & 10 & 7 & 7 & 5 & 4 & 9 & 2 & 4 & 3 & 4 \\
\hline
\end{tabular}

We further comment here on the profiles of larger subgroups. ES students show a competence maximum for initiative and entrepreneurial spirit $\left(\mathbf{I}_{\text {score }}=\right.$

${ }^{16}$ Known by the author through his experience in Erasmus exchanges with UK universities. 
$23.4 \%$ against $8.9 \%$ for the entire incoming sample) as well as for grounding in basic knowledge of the profession (which, however, is among the less affected competences in the entire sample). Moreover, they show a second maxima for capacity for analysis and synthesis, problem solving and project design and management (this latter being again a less affected competence). DE students show a maximum for interpersonal skills $\left(\mathbf{I}_{\text {score }}=51 \%\right.$, well above the whole IN sample value), FR students for decision-making (36\%). This latter value is very similar in almost all Southern country subgroups (ES, PT and RO, but not GR), while among Northern countries UK students perceive only $14 \%$ importance of improvement (the lowest value for this competence) and DE and PL students in their turn perceive 19\%, quite below the value for the whole sample of incoming students $\left(\mathbf{I}_{\text {score }}=25 \%\right)$.

A further, and quite revealing, comparison is the one between Northern and Southern groups of students, made respectively of students from AT, BE, UK, PL, DE and FR (253 students, as a whole) and from ES, GR, PT, HR and RO (264 students). Indeed, in Table 12 we show the gap in the perceived importance of improvement for those competences, which show the largest gap between Southern and Northern country groups. All other competences have a gap smaller than $5 \%$.

\section{Table 12}

Competences which are most improved either in the Southern or in the Northern incoming groups. Southern group includes ES, GR, PT, HR and RO (264 students), Northern group includes AT, BE, UK, PL, DE and FR (253 students)

\begin{tabular}{|l|r|r|r|c|}
\hline \multicolumn{1}{|c|}{ Competence } & Gap & Southern & Northern & $\begin{array}{c}\text { All } \\
\text { incoming }\end{array}$ \\
\hline Capacity for analysis and synthesis & $8,6 \%$ & $14,8 \%$ & $6,2 \%$ & $10,8 \%$ \\
\hline Capacity To Adapt To New Situations & $6,7 \%$ & $49,3 \%$ & $42,7 \%$ & $45,5 \%$ \\
\hline Problem solving & $6,7 \%$ & $40,6 \%$ & $33,9 \%$ & $34,3 \%$ \\
\hline Decision-making & $8,3 \%$ & $29,0 \%$ & $20,7 \%$ & $24,9 \%$ \\
\hline Initiative and entrepreneurial spirit & $15,8 \%$ & $17,6 \%$ & $1,7 \%$ & $8,9 \%$ \\
\hline Oral and written communication & $-9,9 \%$ & $30,5 \%$ & $40,4 \%$ & $35,1 \%$ \\
\hline Knowledge of a second language & $-6,9 \%$ & $61,2 \%$ & $68,1 \%$ & $61,3 \%$ \\
\hline Interpersonal skills & $-9,1 \%$ & $26,2 \%$ & $35,3 \%$ & $29,5 \%$ \\
\hline Appreciation of diversity and multiculturality & $-9,8 \%$ & $24,6 \%$ & $34,4 \%$ & $29,7 \%$ \\
\hline Ability to work in an international context & $-9,4 \%$ & $19,1 \%$ & $28,5 \%$ & $24,3 \%$ \\
\hline $\begin{array}{l}\text { Understanding of cultures and customs of } \\
\text { other countries }\end{array}$ & $-17,6 \%$ & $35,1 \%$ & $52,7 \%$ & $44,5 \%$ \\
\hline
\end{tabular}


The gap for capacity to adapt to new situations and for problem solving as well as the gap for knowledge of a second language is not very relevant if compared to the actual importance value for all incoming students. For the other eight competences shown in Table 12 the gap is one third or more than the importance value for all incoming students. As a general comment, we can say that Southern students, when compared to the Northern colleagues, during their stay in Padova mostly improve competences related to their own growth, while the improvement perceived by the Northern students with respect to the southern colleagues mostly focuses on communication, interpersonal skills and understanding of other and diverse cultures. We underline here the case of capacity for analysis and synthesis, which seems to reveal an environment in Padova, which is quite apt to develop that competence for Latin students. This is reinforced ${ }^{17}$ by the fact that also FR students (nominally in the Northern group, but from a Latin country) perceive an importance of improvement equal to $13 \%$. We also underline the case of initiative and entrepreneurial spirit with a gap, which is much higher than the actual importance value for all incoming students and which is almost exclusively due the ES and PT subgroups of students. These latter belong to several subject areas, with a bias on health subjects.

Some other comments regard competences showing a very little gap between Northern and Southern country groups:

- Research skills is the only competence showing an appreciable importance of improvement $\left(\mathbf{I}_{\text {score }}=10.6 \%\right.$ for the whole incoming sample), but showing no gap between Southern and Northern students $(0.3 \%$ only). This is probably due to the fact that the students who perceive improvement in this competence carry out thesis/project work in Padova, this being their first experience in a research environment.

- Ability to work in an interdisciplinary team shows an almost vanishing gap $(0,03 \%)$, but it has quite a low overall importance (3.3\%): it may simply detect the fact that students incoming to Padova are rarely involved in interdisciplinary educational activities.

A final comment regards a competence which is affected by mobility in a limited way in the whole sample, but which show clear Northern-Southern country effects: Elementary computing skills is truly the less ticked competence (2.7\% importance of improvement for all incoming students). It

17 A similar reinforcement occurs for decision-making where FR students perceive an importance of improvement (36\%) quite similar to ES, PT and RO students (31\%,35\% and $34 \%)$. 
collects 5 cases of country subgroups showing no ticks, all of them included in the Northern countries; among these latter only DE students declare a small importance (1\%). The Southern students on the contrary perceive a 5\% of importance for the development of these skills in Padova. This confirms previous early findings ${ }^{18}$ about digital development in the two sets of countries, even though in the present context it witnesses a rather small gap and it is "measured" with respect to the level of development found in Padova.

\section{IV.3. Exchange and Complementariness of competence improvement}

Another fruitful comparison is between Padova students, outgoing to a given country, and incoming students from that same country. This comparison should reveal the possible complementariness of the two environments, i.e. those related to ordinary and academic life, as experienced by the two "paired" country subgroups. In other words, the same students in different academic and daily life environments develop and/or improve different generic competences; we can say that the students of the "pair" exchange among themselves improved abilities. Erasmus mobility triggers and at the same time reveals the complementariness of competence improvement. We explored these aspects relying on five pairs of country subgroups, i.e. respectively between Padova students outgoing to DE, ES, FR, PL and UK on one side and DE, ES, FR, PL and UK students incoming to Padova on the other side. These pairs enjoy a better statistical base in the present survey.

For each pair we show below - Table 13a, b - which competences are most enhanced in the Padova students, while they stay in the paired country universities, and which ones are most enhanced in the corresponding foreign student colleagues, when they are hosted at Padova University.

In more detail, we see that the improvement of some competences is common to several pairs: the Padova students improve capacity to adapt to new situations with respect to the colleague students in a given pair (in all pairs, except the FR related pair!). Moreover, they improve even more capacity for organization and planning and information management skills (except the ones in the ES pair). On the other end guest students in Padova

${ }^{18}$ An early report from the European Commission about Erasmus exchanges, in the '90s, showed how the Southern students going to Northern countries much benefitted by the computer facilities available there. The reverse was not occurring. 
improve understanding of cultures and customs of other countries (again except those in the ES pair).

An interesting aspect is that Padova students markedly improve critical and self-critical abilities with respect to colleague students in the three Northern pairs (UK, PL, DE), this being most probably linked to the teaching / learning environment. On the other end, UK [and ES] students in Padova perceive a better improvement in capacity to learn. Here the analytical, in depth approach of the traditional Italian academic environment may well play its role.

Some "exchanged" competences appear in a smaller number of pairs. As a first example, take the ES and FR pairs: Padova students in those countries develop a better capacity for applying knowledge in practice with respect to the paired country subgroups in Padova, and vice-versa the FR and ES students in Padova declare a definitely better improvement in capacity for analysis and synthesis. This shows again a complementariness of approaches in teaching learning activities. In these same pairs, the enhancement of decision-making, experienced by guest students in Padova, appears as a surprising feature. As a second example, Padova students in PL and DE show a marked improvement in research skills, most probably because they get involved in thesis work, for which English language is the lingua franca, thus minimizing the effects of not knowing either PL or DE language.

Finally, some competences appear only once, thus revealing singular situations. Not pretending to be exhaustive, we mention here:

FR is the only country - among the above five - where a meaningful difference between the Padova students and the incoming paired subgroup appears in knowledge of a second language, i.e. staying in FR really helps this competence. The opposite situation occurs for PL students in Padova, who really benefit from the stay for learning Italian language, as compared to the Padova colleagues in PL (who should learn Polish!).

Padova students in FR benefit in improving concern for quality and capacity for generating new ideas (creativity), two competences not found in the other pairs.

Padova students in UK benefit in improving basic general knowledge, this being consistent with the synthetic and pragmatic teaching learning approach of UK universities.

ES students in Padova experience a great improvement in initiative and entrepreneurial spirit, a surprise in itself. If we remember the similar - but to a much lower extent - finding, related to all the Southern incoming students (Table 12), we can further confirm that the academic and daily life environments found in Padova are able to trigger quite an improvement of that competence in these subgroups of students. 


\section{Table 13a}

Competence "exchange" between pairs of outgoing and incoming students related to ES and FR respectively. Each pair shows the OUT importance (i.e. I for the sample of all outgoing students, first column) for the listed competence

(second column) as well as the difference between OUT and IN importance (between $\mathbf{I}_{\text {score }}$ of the paired subgroups, third column, rounded values)

\begin{tabular}{|c|l|c|}
\hline $\begin{array}{c}\text { OUT } \\
\text { importance } \\
\text { (all OUT) }\end{array}$ & \multicolumn{1}{|c|}{ ES enhances... } & $\begin{array}{c}\text { OUT - IN } \\
\text { subgroups' } \\
\text { importance } \\
\text { difference }\end{array}$ \\
\hline $69,2 \%$ & Capacity to adapt to new situations & $21 \%$ \\
\hline $14,7 \%$ & Teamwork & $9 \%$ \\
\hline $21,1 \%$ & Ability to work in an international context & $9 \%$ \\
\hline $14,6 \%$ & Research skills & $9 \%$ \\
\hline $9,3 \%$ & Will to succeed & $7 \%$ \\
\hline $20,8 \%$ & Capacity for applying knowledge in practice & $7 \%$ \\
\hline & \multicolumn{1}{|c}{ Padova on ES students enhances ... } & $-18 \%$ \\
\hline $4,1 \%$ & Initiative and entrepreneurial spirit & $-11 \%$ \\
\hline $4,7 \%$ & Capacity for analysis and synthesis & $-10 \%$ \\
\hline $31,0 \%$ & Problem solving & $-10 \%$ \\
\hline $6,9 \%$ & Basic general knowledge & $-10 \%$ \\
\hline $8,6 \%$ & Capacity to learn & $-9 \%$ \\
\hline $21,1 \%$ & Decision-making & \\
\hline
\end{tabular}

\begin{tabular}{|c|l|c|}
\hline $\begin{array}{c}\text { OUT } \\
\text { importance } \\
\text { (all OUT) }\end{array}$ & \multicolumn{1}{|c|}{ FR enhances... } & $\begin{array}{c}\text { OUT - IN } \\
\text { subgroups' } \\
\text { importance } \\
\text { difference }\end{array}$ \\
\hline $24,7 \%$ & Capacity for organization and planning & $16 \%$ \\
\hline $20,8 \%$ & Capacity for applying knowledge in practice & $15 \%$ \\
\hline $12,7 \%$ & Information management skills & $10 \%$ \\
\hline $6,4 \%$ & Concern for quality & $10 \%$ \\
\hline $10,1 \%$ & Capacity for generating new ideas (creativity) & $10 \%$ \\
\hline $68,2 \%$ & Knowledge of a second language & $9 \%$ \\
\hline & \multicolumn{1}{|c|}{ Padova on FR students enhances ... } & $-20 \%$ \\
\hline $25,9 \%$ & $\begin{array}{l}\text { Understanding of cultures and customs of other } \\
\text { countries }\end{array}$ & $-16 \%$ \\
\hline $21,1 \%$ & Decision-making & $-15 \%$ \\
\hline $27,2 \%$ & Appreciation of diversity and multiculturality & $-13 \%$ \\
\hline $9,3 \%$ & Will to succeed & $-7 \%$ \\
\hline $1,6 \%$ & Ability to communicate with not experts & $-7 \%$ \\
\hline $4,7 \%$ & Capacity for analysis and synthesis & \\
\hline &
\end{tabular}




\section{Table 13b}

Competence "exchange" between pairs of outgoing and incoming students related to $\mathrm{PL}, \mathrm{DE}$ and UK respectively. Each pair shows the OUT importance (i.e. $\mathbf{I}_{\text {score }}$ for the sample of all outgoing students, first column) for the listed competence (second column) as well as the difference between OUT and IN importance (between $\mathbf{I}_{\text {score }}$ of the paired subgroups, third column, rounded values)

\begin{tabular}{|c|l|c|}
\hline $\begin{array}{c}\text { OUT } \\
\text { importance } \\
\text { (all OUT) }\end{array}$ & \multicolumn{1}{|c|}{ PL enhances... } & $\begin{array}{c}\text { OUT - IN } \\
\text { subgroups' } \\
\text { importance } \\
\text { difference }\end{array}$ \\
\hline $69,2 \%$ & Capacity to adapt to new situations & $55 \%$ \\
\hline $17,2 \%$ & Critical and self-critical abilities & $15 \%$ \\
\hline $24,7 \%$ & Capacity for organization and planning & $13 \%$ \\
\hline $14,6 \%$ & Research skills & $11 \%$ \\
\hline $12,7 \%$ & Information management skills & $10 \%$ \\
\hline $5,1 \%$ & Ability to work in an interdisciplinary team & $9 \%$ \\
\hline & \multicolumn{1}{|c|}{ Padova on PL students enhances... } \\
\hline $25,9 \%$ & Understanding of cultures and customs of other countries & $-26 \%$ \\
\hline $28,6 \%$ & Oral and written communication & $-18 \%$ \\
\hline $21,1 \%$ & Ability to work in an international context & $-18 \%$ \\
\hline $68,2 \%$ & Knowledge of a second language & $-15 \%$ \\
\hline $21,7 \%$ & Interpersonal skills & $-13 \%$ \\
\hline $27,2 \%$ & Appreciation of diversity and multiculturality & $-13 \%$ \\
\hline $6,9 \%$ & Basic general knowledge & $-11 \%$ \\
\hline
\end{tabular}

\begin{tabular}{|c|l|c|}
\hline $\begin{array}{c}\text { OUT } \\
\text { importance } \\
\text { (all OUT) }\end{array}$ & \multicolumn{1}{|c|}{ DE enhances... } & $\begin{array}{c}\text { OUT - IN } \\
\text { subgroups' } \\
\text { importance } \\
\text { difference }\end{array}$ \\
\hline $69,2 \%$ & Capacity to adapt to new situations & $23 \%$ \\
\hline $12,7 \%$ & Information management skills & $11 \%$ \\
\hline $17,2 \%$ & Critical and self-critical abilities & $9 \%$ \\
\hline $14,6 \%$ & Research skills & $9 \%$ \\
\hline $24,7 \%$ & Capcity for organization and planning & $7 \%$ \\
\hline $14,7 \%$ & Teamwork & $7 \%$ \\
\hline & \multicolumn{1}{|c|}{ Padova on DE students enhances... } & $-31 \%$ \\
\hline $25,9 \%$ & Understanding of cultures and customs of other countries & $-28 \%$ \\
\hline $21,7 \%$ & Interpersonal skills & $-9 \%$ \\
\hline $1,6 \%$ & Ability to communicate with experts in other fields & $-7 \%$ \\
\hline $6,9 \%$ & Basic general knowledge & $-7 \%$ \\
\hline $2,5 \%$ & Ethical commitment & $-6 \%$ \\
\hline $28,6 \%$ & Oral and written communication & \\
\hline
\end{tabular}




\begin{tabular}{|c|l|c|}
\hline $\begin{array}{c}\text { OUT } \\
\text { importance } \\
\text { (all OUT) }\end{array}$ & \multicolumn{1}{|c|}{ UK enhances... } & $\begin{array}{c}\text { OUT - IN } \\
\text { subgroups' } \\
\text { importance } \\
\text { difference }\end{array}$ \\
\hline $69,2 \%$ & Capacity to adapt to new situations & $32 \%$ \\
\hline $17,2 \%$ & Critical and self-critical abilities & $20 \%$ \\
\hline $12,7 \%$ & Information management skills & $12 \%$ \\
\hline $24,7 \%$ & Capacity for organization and planning & $11 \%$ \\
\hline $6,9 \%$ & Basic general knowledge & $9 \%$ \\
\hline $27,2 \%$ & Appreciation of diversity and multiculturality & $9 \%$ \\
\hline & \multicolumn{1}{|c|}{ Padova on UK students enhances... } & $-38 \%$ \\
\hline $25,9 \%$ & $\begin{array}{l}\text { Understanding of cultures and customs of other } \\
\text { countries }\end{array}$ & $-23 \%$ \\
\hline $21,1 \%$ & Ability to work in an international context & $-17 \%$ \\
\hline $9,6 \%$ & Ability to work autonomously & $-15 \%$ \\
\hline $28,6 \%$ & Oral and written communication & $-12 \%$ \\
\hline $8,6 \%$ & Capacity to learn & $-10 \%$ \\
\hline $1,6 \%$ & Ability to communicate with not experts & $-10 \%$ \\
\hline $9,3 \%$ & Will to succeed & \\
\hline & &
\end{tabular}

Finally, the UK students in Padova perceive a significantly better improvement in ability to work autonomously than their Padova colleagues in UK, thus confirming a remark about who/what governs the study progression, as detailed in section IV.2 above.

\section{Discussion and conclusions}

In this paper, we explored the perceived impact of the Erasmus mobility experience on the improvement of the thirty generic competences, which were identified by the Tuning Europe project. The tool through which the students gave their answers is a list of short names, each one standing for a given competence. This was the pragmatic choice of Tuning Europe participants. ${ }^{19}$ We iterate it here, even though with a less refined data processing. Of course, the return given by each student depends on how each short name resonates in her/his mind and experience and depends in addition on her/his self-awareness about the role of generic competences in present

${ }^{19}$ See González and Wagenaar, eds., Tuning Europe, Final Report - Phase 1, 31-32; and González and Wagenaar, eds., Tuning Europe, Universities' Contribution to the Bologna Process, 72-73. 
and future life. The relation between what is evoked in the responding person by the short name of a given competence and the actual dimensions of that same competence in the brain and life of that person should deserve some further attention by the specialists in competence-based learning. The students' returns generate databases, which for each student indicate as a rule five chosen competences, i.e. the ones, which were most improved during her/his Erasmus stay. We then introduce a quantity $\mathbf{I}_{\text {score }}$, which we name "perceived importance of improvement". For a given competence $\mathbf{I}_{\text {score }}$ closely reflects the percentage of ticks, which that given competence received by the responding sample/subsample. At the same time, such a quantity allows direct and consistent comparisons among different samples and subsamples (see Appendix I for technical details regarding its definition).

A second methodological remark concerns the statistics of the samples and subsamples considered here. The two main samples (outgoing and incoming students) should be quite reliable. As to the country subgroups, we decided to include those totaling at least 14 answering students, a number which implies on the average about 70 ticks per competence. Indeed, the least ticked competences receive 45 ticks and 70 ticks, in the outgoing and incoming samples respectively. Most competences get more (or much more) than 100 ticks. As already remarked above, some random fluctuations in the results may very well occur. In some cases, this fact might weaken our interpretations. Nevertheless, the overall resulting picture is consistent in itself and with other findings. In this same context, while we are aware of our weaknesses, we stress the value of this kind of surveys in highlighting qualitative features in the Erasmus student experience.

The main general result is that the two rankings of importance of improvement are quite similar in qualitative terms for the two main samples (outgoing and incoming students), but that they show significant differences in the importance values, as actually perceived by responding students. Thus, we avoid the average ranking, which can nevertheless be calculated straightforwardly. Both samples assign the first two places to capacity to adapt to new situations and to knowledge of a second language, though in a different order and with quite a difference in their importance of improvement values. In three cases, they are identified by two thirds of the samples. The difference in value for capacity to adapt to new situations can significantly be interpreted in terms of the family life of the Italian students as compared to most of their foreign colleagues. Moreover, considering only competences with an $\mathbf{I}_{\text {score }}$ value for the importance of improvement above $27 \%,{ }^{20}$ we find three additional

20 An appropriate threshold between higher and lower values of importance of improvement, identified by inspection. 
competences in the outgoing sample (at a much lower value than the first two, less than one third of respondents) and five in the incoming sample (at values a bit higher than the three of the outgoing sample). This further difference suggests that the outgoing students perceive improvement on a wider set of competences, thus spreading their ticks and lowering the importance value of the improved competences. On the other hand, the incoming sample concentrates its ticks on fewer competences, raising their importance values. This situation may be specific to the city and University of Padova life environments, which are equal for all incoming students, against a variety of situations encountered by the outgoing students in the several visited countries. The three additional competences of the outgoing sample are problem solving, oral and written communication and appreciation of diversity and multiculturality. They also appear in the five additional competences of the incoming sample. The other two competences of the incoming sample are understanding of cultures and customs of other countries, at a quite high value (as high as capacity to adapt to new situations!), and interpersonal skills.

Some significant information can be extracted from the less valued competences. These latter are described at the end of section II. Note that their quite low importance values are referred to the entire main samples (either OUT or IN) and that they hide significant country effects as described in section IV.2.

Indeed, in this piece of work, an important part is played by the comparisons between the two main samples (Section III) and between/among their several country subgroups (section IV). Such an analysis yields a very rich set of findings as well as - when appropriate - of possible interpretations or explanatory remarks, in the attempt of understanding differences.

The comparison between the two main samples leads to a couple of related observations:

- Firstly, focusing on and revealing the differences in the teaching / learning approach between the Italian (Paduan) academic community and those same communities in the partner countries; clear interpretations seem possible.

- Secondly, focusing on some intercultural skills, which apparently are quite fostered by the Paduan environment, but are not perceived by the Italian students abroad as significantly improved. Several interpretations are possible. Moreover, a related finding is that the improvement in understanding of cultures and customs of other countries is clearly decoupled from the improvement in appreciation of diversity and multiculturality. 
As a final comment to this part of our findings, we would like to recall the conclusions of the recent and already quoted Erasmus Impact Study (EIS) ${ }^{21}$ The EIS approach does not distinguish between outgoing and incoming students. Out of the 15 competences examined there, 12 ones, apart from differences in phrasing, coincide with the ones included in the Tuning list. Three competences are new ones: intercultural competences, which is assessed as to be the most improved one, sector-or field-specific skills, which stands low in the Erasmus students EIS rating and to feel European - to have Europe-wide perspectives beyond the national horizon - to have a sense of European citizenship, which again stands low. The interesting aspect is that the group of intercultural competences ${ }^{22}$ in the EIS survey is rated higher than in the findings of the present work. All the other common competences reflect rather well the order found in our two main samples. The only exception is problem solving which goes to the bottom of the EIS rating, most probably because of a rather different phrasing. A second interesting aspect is that the EIS assessment methodology does not yield significant differences in the values of its indicator for competence improvement and, in any case, it offers a kind of macro indicator for all Erasmus students. The simple tool used here yields marked differences among the values for the perceived importance of improvement, which lend themselves to interesting interpretations and show the richness of behaviors at a micro level. Moreover, one can calculate its value for any sample or subsamples or set of subsamples.

In the present analysis, the values of the two main samples are the result of returns from students either going to or coming back from several different countries, each one with its own culture, customs and daily style of life. This allows for exploring possible perceived country effects. The corresponding analysis was carried out from three different perspectives, which complement each other and which with their findings confirm the overall coherence and soundness of the approach. Indeed, we analyzed the students' returns from the point of view of:

- A given competence, to explore which country subgroups, either outgoing or incoming, showed the greatest improvement. See Tables $10 \mathrm{a}$ and $10 \mathrm{~b}$ and related comments in Section IV.1.

- A given country, to detect its "profile" in terms of the perceived importance of improvement for the thirty Tuning competences both for

${ }^{21}$ See European Commission, Erasmus Impact Study, 108.

${ }^{22}$ i.e. using the EIS phrasing: i) intercultural competences, ii) being able to interact and work with people from other backgrounds and cultures, iii) knowledge of the host country's culture, society and economy. 
the outgoing subgroup (visited country) and the incoming subgroup (home country). See Section IV.2.

- The exchange of competences which occurs between paired country subgroups (students outgoing to a given country versus students incoming from that same country). See Section IV.3, where it is shown how the Erasmus students' self-assessment described here reveals in both involved countries' complementariness of the opportunity offered by degree courses and units for improvement in or development of generic competences.

As a conclusion, the main finding of this piece of work is that the Erasmus mobility experience markedly improves several generic competences, but that such achievements are unequal and depend strongly on the home and host university environment, defined as including both the academic milieu experienced by the students and the daily life routine of the country. More precisely, the present study demonstrates, on the basis of several findings and particular cases, the following general issues about the process "generic competence development in Erasmus mobility for study":

a) the development of competences is linked to:

i. the initial environmental conditions;

ii. the actual experience carried out during mobility;

iii. the quality/composition of the student group, which undergoes the mobility experience.

b) The development of competences is a highly individual, complex and non-linear process, as discussed elsewhere within the Tuning community. ${ }^{23}$ Nevertheless, the simple self-assessment tool used in the present work allows the "measurement" of the development of generic competences in an aggregated sample.

c) Erasmus, a well known jewel in itself, is extraordinarily able to exemplify concretely the motto "united in diversity" in terms of improved generic competences. The same experience - the Erasmus exchange mobility - originates different individual and group growth.

${ }^{23}$ See for instance Lokhoff, Jenneke et al., eds. A Guide to Formulating Degree Programme Profiles (Bilbao, Groningen and The Hague: Publicaciones de la Universidad de Deusto, 2010. 


\section{Bibliography}

Bracht, Oliver, Constanze Engel, Kerstin Janson, Albert Over, Harald Schomburg and Ulrich Teichler. The Professional Value of ERASMUS Mobility. INCHER - International Centre for Higher Education Research. Kassel: University of Kassel, 2006.

Corriere Università. Sempre più "mammoni”: Italiani fanalino d'Europa, February 9, 2015. Accessed at http://www.corriereuniv.it/cms/20Ita15/02/giovaniitaliani-preferiscono-restare-casa-in-francia-uk-meta/

Directorate General Education and Culture. Survey into the socio-economic background of Erasmus students. Brussels: European Commission, 2000.

European Commission. Erasmus+ Programme guide, valid as 1 January 2014, at http://ec.europa.eu/programmes/erasmus-plus/discover/guide/2014/documents/ erasmus-plus-programme-guide_en.pdf

- Erasmus Impact Study, Effects of mobility on the skills and employability of students and the internationalisation of higher education institutions. Luxembourg: Publications Office of the European Union, 2014. Accessed November 12, 2015, doi: 10.2766/75468.

González, Julia, and Robert Wagenaar, eds. Tuning Educational Structures in Europe, Final Report, Pilot Project - Phase 1, carried out by over 100 Universities, coordinated by the University of Deusto (Spain) and the University of Groningen (The Netherlands) and supported by the European Commission”. University of Deusto and University of Groningen, 2003.

- Tuning Educational Structures in Europe. Universities' Contribution to the Bologna Process. An Introduction. 2nd ed. Bilbao: Universidad de Deusto, 2008.

Haselberger, David, Petra Oberhuemer, Eva Perez, Maria Cinque, and Fabio Capasso. ModES Handbook: Mediating Soft Skills at Higher Education Institutions, Guidelines for the design of learning situations supporting soft skills achievement, 2012. Accessed November 12, 2015. http://www. modesproject.eu/en/the-modes-handbook.aspx.

Lokhoff, Jenneke, Bas Wegewijs, Katja Durkin, Robert Wagenaar, Julia González, Ann Ka therine Isaacs, Luigi F. Donà dalle Rose and Mary Gobbi, eds. A Guide to Formulating Degree Programme Profiles. Bilbao, Groningen and The Hague: Publicaciones de la Universidad de Deusto, 2010.

Managing Committee of the EMQT-Erasmus Mobility Quality Tools European Project (2009-2011), eds. "Academic Quality in exchange mobility” in Outcomes of the EMQT project, 83-129. Padova: Universities of Bologna, Deusto and Padova, 2012.

Villa Sanchez, Aurelio, and Manuel Poblete Ruiz, eds. Competence-based learning, A proposal for the assessment of generic competences. Bilbao: Deusto University Press, 2008. 


\section{Appendix I. How to compare percentage values of the parameter importance of improvement in different samples}

As discussed in Section I, a straightforward definition for the parameter importance of the improvement of a given competence in a given sample might be the percentage ratio of "number of students who ticked that very competence" over "number of students who answered the question regarding competences".

A related - but somewhat clumsier - way to define the importance of improvement is the number of ticks assigned to a given competence over the "total number of ticks divided by 5" (i.e. a kind of average number of ticks per selected competence). We call this related quantity the renormalized percentage importance and we indicate it with the symbol $\mathbf{I}_{\text {score. }}$. Indeed, it is simply equal to the percentage ratio, as defined right above, multiplied by an appropriate re-normalization factor. This factor, usually very close to unity, takes into account the fact that the number of ticks per answering student in the OUT and IN samples (or any envisaged subsample of these two main ones) varies, see Table 1 of the main text as an example. The renormalization factor - say $\mathrm{f}_{\text {sample }}-$ is equal to

$$
\begin{gathered}
\mathrm{f}_{\text {sample }}=(\text { number of respondents in the given sample }) / \\
{[(\text { number of their ticks }) / 5],}
\end{gathered}
$$

it varies according to the sample considered and for each sample it renormalizes the sum of the importance of improvement over the 30 competences to $500 \%$, i.e. $100 \%$ times 5 , which should be the number of selected "mostly improved competences" in the end-of-stay questionnaires. Such a renormalization does not influence the order of importance or other meaningful facts described for a single sample in the main text, but is most appropriate when comparing the actual values of importance between the OUT and IN samples. It is also appropriate for comparisons with any chosen subsample (e.g. country subgroups, see main text). For the sake of exemplifying, we give the value of $\mathrm{f}_{\text {sample }}$ for the two main samples discussed here, i.e. 1.0317 and 1.1464 for the OUTgoing and INcoming sample respectively. These numbers are calculated on the basis of Table 1 data.

Finally, we emphasize that because of the lack of clearness in phrasing the step 2 of the competence related question, it was not possible to calculate the importance using the method adopted by Tuning Europe - phase $1 .{ }^{24}$

${ }^{24}$ See Julia González and Robert Wagenaar, eds., Tuning Educational Structures in Europe, Final Report, Pilot Project - Phase 1, carried out by over 100 Universities, 
Nevertheless, we did a check on the sub-sample of outgoing students, who answered correctly to step 2 of the question, giving their own ranking of the five selected competences. The order of importance calculated using the Tuning Europe method for such a sub-sample reflects almost exactly the order of importance for the whole sample of outgoing students, based on the simpler percentages of ticks. Indeed, they are exactly the same for the first ten competences, except for capacity for organization and planning which shifts from $4^{\text {th }}$ to $7^{\text {th }}$ place, when commuting from the first (Tuning way) ordering to the second one (present piece of work).

\section{About the Author}

LUIGI F. DONÀ DALLE ROSE (dona@pd.infn.it) holds a "laurea in Fisica" from the University of Padova, Italy (1964). He taught there since 1970 till 2011, being appointed as a professor in Theoretical Physics in 1980. He taught Statistical Mechanics, Solid State Physics, Many Body Theory, Quantum Physics. His research activities cover mainly: band theory of metals, quantum electron gas, heat transients by ultra-short laser pulses, solid-liquid metal interface. Since 1995, he took interest In Physics education. From 1990 until 2015, professor Donà dalle Rose was Delegate and later Consultant of the Rector for European Student Mobility at the University of Padova, being also actively committed at grass-root level in Erasmus exchanges and other European projects, among these latter as a participant in CoRe2 and as coordinator of EMQT-Erasmus Mobility Quality Tools. He was cofounder and member of the Steering Committee of the Socrates TNP-Thematic Network Project for Physics and member of the Coimbra Group Executive Board 2007-2013. He was also a member of the Management Committee of the Tuning project and co-Chair of the Tuning Physics Subject Area Group (2000-2008) in Europe. He was a member and expert of the Italian Team of Bologna experts along its duration (2004-2013).

coordinated by the University of Deusto (Spain) and the University of Groningen (The Netherlands) and supported by the European Commission (University of Deusto and University of Groningen, 2003), 80-81. 


\section{Copyright}

Copyright for this article is retained by the Publisher. It is an Open Access material that is free for download, distribution, and or reuse in any medium only for non-commercial purposes; provided any applicable legislation is respected, the original work is properly cited, and any changes to the original are clearly indicated. 